WIDER Working Paper 2020/77

\title{
Precarity and the pandemic
}

COVID-19 and poverty incidence, intensity, and severity in developing countries

Andy Sumner, ${ }^{1}$ Eduardo Ortiz-Juarez, ${ }^{2}$ Chris $\mathrm{Hoy}^{3}$

June 2020 


\begin{abstract}
This paper makes a set of estimates for the potential impact of the COVID-19 pandemic on poverty incidence, intensity, and severity in developing countries and on the distribution of global poverty. We conclude there could be increases in poverty of a substantial magnitude-up to 400 million new poor living under the $\$ 1.90$ poverty line, over 500 million new poor living under the poverty lines of $\$ 3.20$ and $\$ 5.50$. Further, the global income shortfall below each poverty line could expand by up to 60 per cent; the daily income losses could amount to $\$ 350 \mathrm{~m}$ among those living under $\$ 1.90$ per day and almost $\$ 200$ million among the group of people newly pushed into extreme poverty. Finally, we present country-level poverty estimates that show the location of global poverty is likely to shift towards middle-income countries and South Asia and East Asia. Our estimates are indication of the range of potential outcomes. If anything, our estimates show the extent of precarity in developing countries and the fragility of much poverty reduction to any economic shock.
\end{abstract}

Key words: COVID-19, crisis, global poverty, precarity, SDGs, vulnerability

\title{
JEL classification: I32
}

Acknowledgements: We would like to thank Giovanni Valensisi for the comments.

${ }^{1}$ King's College London, ${ }^{2}$ King’s College London, ${ }^{3}$ Australian National University. Corresponding author: andrew.sumner@kcl.ac.uk

This study has been prepared within the UNU-WIDER project on Academic Excellence.

Copyright (C) UNU-WIDER 2020

Information and requests: publications@wider.unu.edu

ISSN 1798-7237 ISBN 978-92-9256-834-4

https://doi.org/10.35188/UNU-WIDER/2020/834-4

Typescript prepared by Lorraine Telfer-Taivainen

United Nations University World Institute for Development Economics Research provides economic analysis and policy advice with the aim of promoting sustainable and equitable development. The Institute began operations in 1985 in Helsinki, Finland, as the first research and training centre of the United Nations University. Today it is a unique blend of think tank, research institute, and UN agency — providing a range of services from policy advice to governments as well as freely available original research.

The Institute is funded through income from an endowment fund with additional contributions to its work programme from Finland, Sweden, and the United Kingdom as well as earmarked contributions for specific projects from a variety of donors.

Katajanokanlaituri 6 B, 00160 Helsinki, Finland

The views expressed in this paper are those of the author(s), and do not necessarily reflect the views of the Institute or the United Nations University, nor the programme/project donors. 
Much attention has, understandably, focused on the health-related aspects of the COVID-19 pandemic and on the potential magnitude of the contraction in countries' economic output. The impact that unemployment and labour income shocks as a consequence of the lockdown measures can exert on poverty rates in developing countries has received relatively less attention to date. This is concerning because many developing countries are characterised by fragmented social protection systems often decoupled from the informal labour market where much of the population works. Any lockdown likely implies the income-generating capacities of this group of people in particular are very limited.

This paper builds on the initial discussion of Sumner et al. (2020) and presents estimates of the potential short-term impact of the pandemic on poverty in developing countries using a range of shocks in household per capita consumption or income. ${ }^{1}$

The shocks are contrasted with the World Bank's poverty lines of $\$ 1.90, \$ 3.20$, and $\$ 5.50$ a day ${ }^{2}$ equivalent, respectively, to the median values of the national poverty lines among low-income, lower-middle-income, and upper-middle-income countries (see Jolliffe and Prydz 2016). Our approach implicitly focuses on precarity or vulnerability-to-poverty. Specifically, we use an augmented poverty line approach and make use of the World Bank's PovcalNet built-in dataset of harmonised household surveys across 166 economies. Unless otherwise stated, all monetary amounts in this paper are expressed in international dollars at 2011 purchasing power parity (PPP) exchange rates.

The paper comes with the set of limitations one would expect. Importantly, our estimates are a range of potential outcomes. The final poverty outcome will be determined by what governments do, the precise income shock in each country, and the duration of the crisis. Moreover, we make the simplifying assumption that the effects of contractions in household per capita incomes or consumption are distribution neutral, even though there is good reason to believe that the poor and near poor in developing countries will be disproportionally affected as the share of informal jobs, particularly impacted by lockdowns, is significant and interacts with absent or deficient social protection systems. Finally, there are crucial non-monetary poverty impacts in the dimensions of health, education, and living conditions that are not captured in our range of estimates.

This paper makes three contributions to the nascent literature on the welfare impacts of COVID19 on households in low- and middle-income countries. Firstly, we move beyond other studies on this topic that have only focused on a subset of countries (e.g., ILO 2020a, 2020b; Vos et al. 2020a, 2020b; Laborde et al. 2020) or have relied on the April 2020 IMF WEO forecasts for economic growth (e.g., Lea 2020; Maher et al. 2020; Valensisi 2020) that assume the crisis will 'fade' after June 2020 (IMF 2020: 1). We do so by considering a range of scenarios of the depth of the economic crisis. Secondly, we extend the discussion by providing estimates of the aggregate consumption shortfall below the $\$ 1.90, \$ 3.20$ and $\$ 5.50$ poverty lines brought about by the crisis, which in most of our scenarios is in excess of $\$ 100$ million a day. Thirdly, we add detail about the

\footnotetext{
${ }^{1}$ Some countries have income data and others have consumption data in the dataset exploited. As poverty rates tend to vary in the same country when using either income or consumption, and in order to avoid a misleading interpretation, we refer simply to 'welfare'.

2 A new series of 2017 PPP exchange rates was published in May 2020 and thus these poverty lines will be revised to $\$ 2.10, \$ 4.00, \$ 6.30$ a day, respectively (see Atamanov et al. 2020).
} 
country level impact of COVID19 and illustrate there will likely be a dramatic spike in poverty rates in some of the middle-income countries that have made significant progress in recent years.

This paper is structured as follows: Section 2 discusses our methodology and reviews the other poverty estimates we are aware of, paying special attention to why we chose not to use a method based on country-specific GDP per capita growth forecasts. Sections 3 and 4 present the estimates at the global and regional levels and discuss how the crisis may shift the overall pattern of global poverty. Section 5 focuses on national-level poverty impacts across the developing world. Section 6 concludes.

\section{Methodology}

\subsection{Our approach}

Our range of estimates of the potential impact of COVID-19 on monetary-based poverty uses the World Bank's PovcalNet built-in dataset of harmonised household surveys. PovcalNet provides information on nationally representative per capita income or consumption measures for 166 developing and advanced economies, and hence allows for the computation of the extent of poverty at an internationally comparable basis through well-known indices such as the poverty headcount ratio, the poverty gap, and the squared poverty gap (see Foster et al. 1984). ${ }^{3}$

The reference year, or status quo, for our estimates is 2018, for which per capita income or consumption measures are available for the 166 countries. India is the only exception, as its latest available extrapolated measure corresponds to $2015 .{ }^{4}$ Given the lack of more recent information for this populous country, we acknowledge that computing its potential short-term poverty changes using the welfare measure recorded in 2015 as a baseline could somewhat inflate the estimates, though the opposite may also be the case. The poverty rate in India could be lower given the sustained decline in poverty that the country has been experiencing since 1990, from about 48 per cent of the total population in that year to just above 13 per cent by 2015, according to the $\$ 1.90$ a day poverty line. However, how exactly the poverty rate changed between 2015 and 2018 is highly contentious. Felman et al. (2019) discuss the leaked report of India's National Sample Survey (NSS) that had been withheld by the government (the long-standing survey has now been abandoned). The survey showed real consumption per capita had fallen by 3.7 per cent between $2011 / 12$ and 2017/18. This figure sits uneasily with the official GDP growth data reported for the same period. In short, by using the 2015 data our estimates could overestimate poverty in 2018 in India if the GDP growth data is correct. On the other hand, if the NSS consumption per capita data is accurate, our estimates will thus underestimate it.

We use three scenarios of a contraction in per capita income or consumption as a consequence of the lockdown set in place to contain the spread of the COVID-19 disease: 5, 10, and 20 per cent contraction. Although apparently arbitrary at first sight, the chosen contractions are closely related

\footnotetext{
3 These series are typically employed by the World Bank to report reference-year estimates of global and regional aggregates of poverty. As noted by Castañeda et al. (2019), since many countries have no available survey data in every year, extrapolations or interpolations of household per capita income or consumption are required to estimate poverty figures in a given reference year that is common to all countries in the dataset.

${ }^{4}$ Our estimates at the global and regional level in this paper differ slightly from those we reported previously in Sumner et al. (2020). In our initial work we based our estimates on region-level data using 2018 as reference year for all regions, with the only exception of South Asia for which the reference year was 2015. In this current paper we based our estimates on national-level data.
} 
to recent estimates of potential economic downturns and seek to capture a range of shocks associated. At the lower end, our 5 per cent contraction scenario is just above the updated 2020 forecast for mid-April 2020 from the International Monetary Fund (IMF) projecting a crosscountry median decline of 4.8 per cent in gross domestic product per capita. Among developing countries, the per capita decline in the median economy is estimated at 4.2 per cent, whereas among advanced economies the corresponding projected decline is 7.5 percent. ${ }^{5}$ Our moderate scenario, which involves a 10 per cent contraction, is in line with recent estimates by the ADB (2020) based on a model of the effect of the pandemic on global GDP growth being contained within a sixmonth timeframe- the time it takes from outbreak intensifying to normalizing economic activity post-lockdown.

In the case of our worst scenario, a contraction of 20 per cent is close to the OECD estimates that a partial or complete nation-wide lockdown could result in a contraction ranging between 15 and 35 per cent among 48 major economies, with a 25 per cent short-term decline in the median economy across developing and advanced economies (OECD 2020). In addition, estimates by Goldman Sachs of the effects that lockdowns could exert on the economy suggest that the type or length of measures implemented by Italy and South Korea are associated, respectively, with an output contraction of 25 and 10 per cent. They also estimate an output contraction of 45 per cent in the case of India in the April-June 2020 period. $^{6}$

Given that we do not observe income or consumption for each individual included in the PovcalNet database, we capture our contraction scenarios and their effect on poverty rates by focusing implicitly on precarity or vulnerability-to-poverty and following an augmented poverty line approach. Specifically, as the PovcalNet database allows the user to compute poverty rates at whatever value of the poverty line $z$, we increase such value, namely $z^{a}$, by the corresponding contraction $x_{a}$ in per capita income/consumption measures (with $a=5,10$, and 20 per cent contractions) as

$$
z^{a}=\frac{z}{\left(1-x_{a}\right)}
$$

For example, to determine the increase in poverty of a contraction of 10 per cent in individuals' welfare, we inflate the value of the poverty line of $\$ 1.90$ a day to $\$ 2.11$ a day, then calculate the headcount at this line and subtract that at the original line. For the three contraction scenarios, we thus employ the augmented values of the poverty lines of $\$ 1.90, \$ 3.20$ and $\$ 5.50$ a day. These augmented poverty lines will capture the same number of people falling into poverty as would be recorded if each individual's income or consumption was observed and then contracted by a rate $x_{a}$ to compute new poverty rates.

It is important to highlight that our approach has some important limitations. First, we use extrapolated series of individuals' welfare to our reference year, 2018, which is likely biasing the true poverty rates for such year. Only 29 out of the 166 countries for which the estimates are made have a household survey for 2018, while for the remaining 137 countries extrapolation was

\footnotetext{
5 per cent changes in gross domestic product per capita at constant prices, adjusted by purchasing power parity, as reported in the April 2020 update of the IMF's World Economic Outlook Database. The simple average per capita decline across all countries is 4.7 per cent, and 3.9 and 7.7 per cent, respectively, when looking separately at developing and advanced economies.

${ }^{6}$ Goldman Sachs' estimates cited in 'The 90\% economy that lockdowns will leave behind', The Economist, 20 April 2020, and 'India's economy set to contract by 45\%, Goldman says', The Financial Times, 18 May 2020.
} 
performed. Extrapolation however assumes both that each country's mean income or consumption in the closest survey year will grow towards 2018 at the rates recorded in the national accounts and that such growth will occur evenly across the entire distribution (Castañeda et al. 2019).

Second, there are pernicious impacts of the crisis beyond changes in welfare levels that could have long-lasting effects on human development and capabilities, chiefly health, education, and nutrition. For instance, UNDP (2020: 6) estimates a global decline in a COVID-19-adjusted version of the human development index mostly driven by the education dimension, which could mark the first decline since the inception of the index in 1990 and could be 'equivalent to erasing all the progress in human development of the past six years'. Moreover, it has been estimated that approximately 470 million people globally are at high risk of contracting COVID-19 as a result of pre-existing conditions of malnutrition, lack of access to safe drinking water, and indoor air pollution through the use of noxious cooking fuel (Alkire et al. 2020). Those impacts on human development and capabilities are not captured in our estimates. Neither do our estimates include the policy changes to social protection programmes that governments of many developing countries have introduced or adapted, or are planning to introduce or adapt, in response to the pandemic (see Gentilini et al. 2020).

Thirdly, we assume that the contractions are distribution neutral, but it is not unreasonable to expect that among the poor and near poor they are bigger in the short-run, with a sluggish recovery and by many multiples potentially, than economy-wide forecasts. This is especially so in low- and middle-income countries where the share of informal jobs, particularly affected by lockdown measures, ${ }^{7}$ is significant and interacts with pre-existing social protection systems that are fragmented and whose benefits are typically linked to formal labour markets. ${ }^{8}$ In light of this, we consider that our 10 and 20 per cent contraction scenarios provide a better picture of the potential adverse impacts on those living near the bottom of the distribution regardless of the size of the economy-wide contraction (see Mahler et al. 2020, who also acknowledge this).

Fourthly, there is a further issue of how closely GDP per capita declines are correlated to a household per capita welfare contraction; and that the pass through is unlikely to act symmetrically during positive and negative GDP growth (see discussion in Valensisi 2020). It is also worth noting that financial market crises tend to hit GDP figures worse than household welfare. In contrast, economy-wide shutdowns may actually impact the latter more disproportionately.

In sum, we do not know which of our contraction scenarios will be closest to the final outcome, nor how changes in consumption or income will differ across countries. The final poverty outcome will be determined by what governments do, the duration of the crisis, and the precise income shock in each country and how it distributes across the different sectors. Our estimates are

${ }^{7}$ ILO (2020b) projects that just the first month of the crisis could mean the earnings of informal workers would decline by 82 per cent in low- and lower-middle-income countries, and by 28 per cent in upper-middle-income economies. See also Hatayama, Viollaz and Winkler (2020) who construct a working from home index for 53 developing and advanced economies, showing that informal workers have jobs that are less amenable to working from home, and that such amenability is positively correlated with the country's level of economic development. A similar finding is provided by Dingel and Neiman (2020) who also show that the share of jobs that could be performed at home is less than 25 per cent for most developing countries.

${ }^{8}$ Estimates of workers in informality who cannot rely on employment-based social protection programs reach 60 per cent of the world's employed population or 80 per cent of total workers in developing countries. See, respectively, ILO (2018) and Packard et al. (2019). 
indications of orders of magnitude and should be read not as predictions but as a range of potential outcomes.

\subsection{Comparisons with other studies}

Some existing studies have provided insights into the potential damaging consequences of the COVID-19 pandemic in terms of poverty outcomes. Starting with a focus on the working population, a first study by ILO (2020a) models the impact of the pandemic on labour income using a set of scenarios of potential macroeconomic impacts of COVID-19. It estimates an increase in working poverty, as measured at the $\$ 3.20$ a day poverty line, of 8.8 to 35 million new working poor under a low- and a high-contraction scenario, respectively, with 15 per cent of the new poor living in low-income countries and the remaining share in both lower-middle- and uppermiddle-income economies. ${ }^{9}$ In a second study covering 64 countries, ILO (2020b) estimates that the loss of earnings among informal workers as a result of the pandemic could increase the share of those who earn less than 50 per cent the median earnings, or relative poverty, from 18 to 74 per cent among low- and lower-middle-income countries, and from 26 to 47 per cent in upper-middleincome countries.

In another set of studies, Vos et al. (2020a, 2020b) and Laborde et al. (2020) use a global computable general equilibrium model combined with household-level models for more than 300,000 households from 31 developing countries, mainly from sub-Saharan Africa (SSA) and South Asia, to assess the welfare effects of changes in growth. In the first study, Vos et al. report that a decline of one percentage point in GDP could increase poverty, as measured at the $\$ 1.90 \mathrm{a}$ day poverty line, by about 14 million people, with two thirds of the new poor living in rural areas. In their second, more comprehensive analysis that models whether the economic slowdown occurs through productivity or trade disruption, they show that a one percentage point decline in GDP could result in up to 22 million new poor. Finally, Laborde et al. estimate that, absent interventions, there could be 140 million new poor as a result of COVID-19 in 2020, of which 80 million would be in SSA and 42 million in South Asia.

Without restricting the analysis either to workers or to specific developing regions, the United Nations' Department of Economic and Social Affairs uses the global economy forecasts from its World Economic Forecasting Model and estimates that a total of 34.3 million people could fall below the $\$ 1.90$ a day poverty line globally-in comparison to a baseline of just below 630 million poor people in 2019 (UN 2020). Also pursuing a global coverage and moving away from modelling techniques, Lea (2020), Mahler et al. (2020), and Valensisi (2020) exploit the PovcalNet dataset, as our paper does, to quantify the impact of COVID-19 on global poverty using the IMF's per capita growth forecasts produced in mid-April 2020.

As Table 1 below shows, the results of the latter studies are somewhat consistent in orders of magnitude with our own estimates of the poverty impact at $\$ 1.90$ a day under the 5 per cent contraction scenario. Specifically, we project that 80 million people could fall into extreme poverty as a result of the decline in per capita income or consumption, thus moving the world's absolute incidence upwards from 727 million in the status quo to 807.5 million, and the poverty headcount ratio from 9.9 per cent to 11 per cent. This latter rise of 1.1 percentage points in the relative incidence is close to that computed by Lea, Mahler et al., and Valensisi, who estimate an increase in the world's headcount ratio ranging 0.8 to 1 percentage points.

\footnotetext{
${ }^{9}$ The low and high contraction scenarios used by ILO correspond, respectively, to a GDP growth decline of about two and eight per cent, as estimated by McKibbin and Fernando (2020).
} 
When comparing the incidence and absolute changes in all four studies, some differences become evident which stem from factors beyond methodological choices. Notably, the baselines for precrisis poverty incidence differ. We use a figure of 727 million people that results from aggregating country-level totals for the reference year 2018, whilst Lea employs an estimate of 670 million people that was projected to be the total number of poor by end-2020 in the absence of the pandemic -according to a model based on the partial growth elasticity of poverty changes using PovcalNet's poverty headcounts and the IMF's pre-crisis per capita growth forecasts. Lea adjusted this model according to the updated IMF growth projections and thus the end-2020 estimates changed to 742 million people, yielding 72 million additional poor people than would otherwise been the case. Mahler et al. use a baseline of 603.1 million people in 2020 that results from extrapolating the welfare measures in PovcalNet's household surveys with the pre-crisis growth forecasts. After updating this extrapolation according to the IMF's new projections, they estimate the total number of poor by 2020 to reach 665 million, thus an extra 61.9 million poor in comparison with the baseline. Finally, Valensisi follows the augmented poverty line approach used in Sumner et al (2020) and in this paper and compute an increase in poverty of 68.6 million resulting from adjusting the poverty line by a rate that reflects the IMF's pre- and post-crisis growth forecasts, thus yielding absolute headcounts of, respectively, 642.3 and 710.8 million poor.

Table 1: Estimates of the impact of COVID-19 on global $\$ 1.90$ poverty according to different approaches

\begin{tabular}{|c|c|c|c|c|}
\hline & Our estimates & Lea (2020) & $\begin{array}{c}\text { Mahler et al. } \\
(2020)\end{array}$ & $\begin{array}{c}\text { Valensisi } \\
(2020)\end{array}$ \\
\hline \multicolumn{5}{|l|}{ Status quo in $2018^{\mathrm{a}}$} \\
\hline Headcount rate & $9.9 \%$ & -- & -- & -- \\
\hline Millions & 727.3 & -- & -- & -- \\
\hline \multicolumn{5}{|l|}{ Status quo in 2020 (as projected) $^{b}$} \\
\hline Headcount rate & -- & $8.6 \%$ & $7.8 \%$ & $8.2 \%$ \\
\hline Millions & -- & 670.0 & 603.1 & 642.3 \\
\hline \multicolumn{5}{|l|}{ Forecasts taking COVID-19 in to account } \\
\hline Headcount rate & $11.0 \%$ & $9.6 \%$ & $8.6 \%$ & $9.1 \%$ \\
\hline Millions & 807.5 & 742.0 & 665.0 & 710.8 \\
\hline \multicolumn{5}{|l|}{ Changes relative to status quo } \\
\hline in headcount rate (percentage points) & 1.1 & 1.0 & 0.8 & 0.9 \\
\hline in millions of poor & 80.1 & 72.0 & 61.9 & 68.6 \\
\hline \multicolumn{5}{|l|}{ Meth odological choices } \\
\hline Estimation method & $\begin{array}{l}\text { Augmented } \\
\text { poverty line }\end{array}$ & $\begin{array}{c}\text { Growth } \\
\text { elasticity of } \\
\text { poverty change }\end{array}$ & $\begin{array}{c}\text { Extrapolation of } \\
\text { welfare aggregates }\end{array}$ & $\begin{array}{l}\text { Augmented } \\
\text { poverty line }\end{array}$ \\
\hline Shock assumed & $5 \%$ & Cour & try forecast from IM & \\
\hline
\end{tabular}

Notes: astatus quo based on PovcalNet's country-level extrapolated data from the closest survey year towards the reference year 2018 for 166 countries with the only exception of India for which the reference year used in the estimates is 2015. 'b Status quo based on projected poverty figures using GDP per capita growth rates forecasted in the absence of the COVID-19 crisis. All sets of figures are based on PovcalNet data. All three approaches are distribution-neutral.

Source: authors' estimates based on PovcalNet.

A more important difference between these studies and our estimates relates to the size of the contraction assumed. In contrast to Lea's, Mahler's et al., and Valensisi's approaches, we choose not to use the IMF's updated growth forecasts for a number of reasons. On one hand, the GDP per capita growth forecasts average the equivalent to a contraction of just 1.9 per cent in the top10 countries by number of poor people, jointly accounting for 472.6 million, or 65 per cent, of the world's poor in 2018 - including positive growth rates in Uganda and in populous Ethiopia and India, which together are home of a fifth of the world's population. As these studies apply the forecasts evenly across the countries' population, an IMF's projected positive growth rate of, for 
instance, 0.55 per cent for India, would imply that millions of people will avoid poverty during a pandemic.

Using these relatively modest country-level contractions, and even positive growth figures, forecasted by the IMF to build global poverty estimates seems optimistic. These forecasts are based on the COVID-19 pandemic ending in the second half of 2020 as IMF (2020: 1) notes, "[i]n the baseline scenario, which assumes that the pandemic fades in the second half of 2020 and containment efforts can be gradually unwound'. Since the release of these forecasts, lockdowns have been extended well beyond what was thought to be the case throughout the developing world. For example, the positive growth forecast by the IMF for India was based on the nationwide lockdown announced on 24 March ending in mid-April, however at the time of writing (31 May 2020) this lockdown is still in place in many countries to greater or lesser degrees, which is three times longer than anticipated in the IMF growth estimates. Some estimates suggest that lockdown policies may be established as a new norm or open/shut economies for at least up to 2022 (Kissler et al. 2020).

Furthermore, it is not unreasonable to expect that the household per capita income or consumption contraction among the poor and near poor will be bigger in the short term. In light of this, we consider a 5 per cent contraction in per capita welfare ${ }^{10}$ to better capture the potentially larger losses among the near-poor in developing countries-and even more so our 10 and 20 per cent contraction scenarios, which implicitly assume a bigger shock at the bottom regardless of the size of the economy-wide contraction.

Finally, as Sandefur and Subramanian (2020: 3-4) discuss, 'IMF growth forecasts are a black box ... the IMF forecasts are an aggregation of subjective judgements made by the various area units within the Fund, subject to consistency checks by the research department'. In short, instead of a global model accounting for interdependency between countries or multiple recessions concurrently in developed economies, country-level forecasts are made on an individual basis and with methodologies that 'vary from country to country and series to series'. These features could also lead to inconsistencies when compared to other country-level forecasts. ${ }^{11}$

\section{Global estimates}

Figure 1 presents the poverty headcount ratios and absolute number of poor at different poverty lines for 1990-2018 and our estimates based on the three different scenarios of contraction in per capita income/consumption. Starting with extreme poverty, as measured at $\$ 1.90$ a day, the data reveals that a 5, 10, and 20 per cent shock would push the relative incidence of global poverty upwards for the first time since 1990, from 9.9 per cent of the world's population in the status quo to $11,12.2$, and 15.3 per cent, respectively. In absolute terms, these changes are equivalent to between 80 and almost 400 million people falling into poverty at $\$ 1.90$ a day (Table 2) and suggest a reversal of seven to ten years progress in the fight against poverty reduction, depending on the contraction, and the first absolute increase in people living in extreme poverty since 1999.

\footnotetext{
${ }^{10}$ As noted previously, this 5 per cent shock is slightly above the median GDP per capita contraction forecasted by the IMF, both globally ( -4.8 per cent) and among developing countries ( -4.2 per cent).

${ }^{11}$ See the World Economic Outlook Database website for an overall description of this approach and the assumptions made. For instance, the IMF forecast a GDP per capita contraction of 2.9 per cent and 0.5 per cent in Malaysia and Indonesia in 2020, respectively, whereas the revised World Bank's (2020) projections point to even deeper declines: 4.6 per cent and 3.5 per cent, respectively.
} 
Figure 1: Global poverty incidence at $\$ 1.90, \$ 3.20$, and $\$ 5.50$ a day: $1990-2018$ and estimates under a 5,10 , and $20 \%$ per capita income/consumption contraction (\% of world's population and millions of poor)

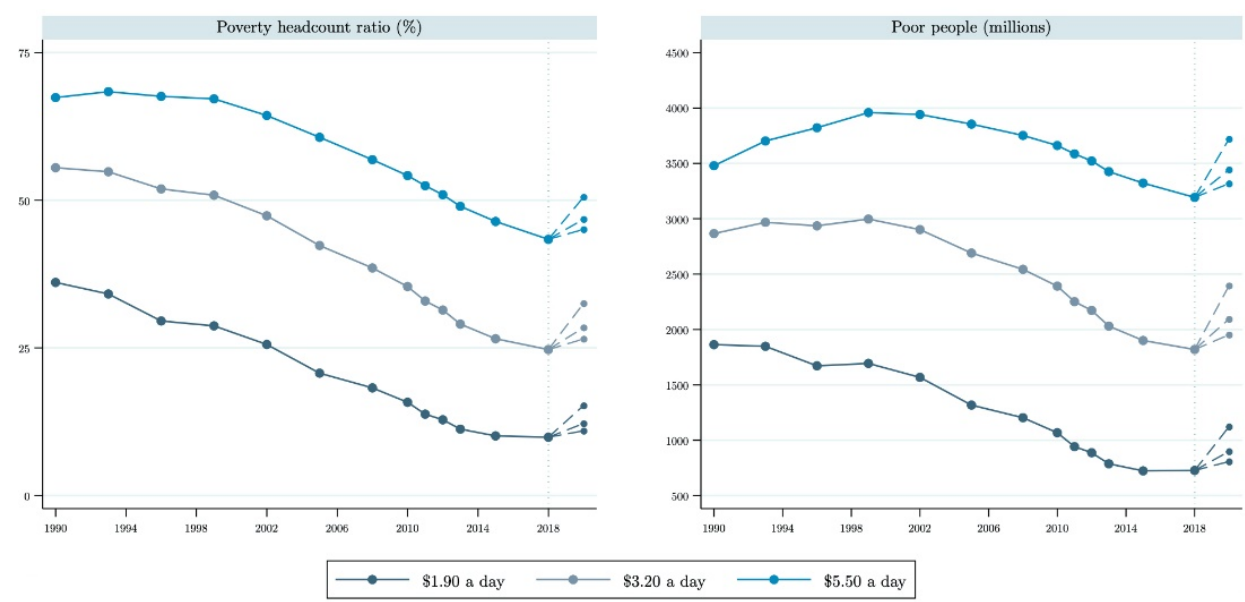

Note: dashed lines after 2018 represent the estimated increase in the incidence of poverty for each poverty line under the income/consumption contraction scenarios, with the lower, middle, and upper dashed lines representing, respectively, the 5,10 , and 20 per cent contraction.

Source: authors' estimates based on PovcalNet.

Using the $\$ 3.20$ a day poverty line, equivalent to the median value of the poverty lines among lower-middle-income countries, the estimates suggest an increase from 24.7 per cent in the status quo to 26.5 per cent under a 5 per cent shock and up to 32.6 per cent in the worst-case scenario. This implies that the number of people considered poor by the $\$ 3.20$ a day poverty line would expand by 133 to 576 million. Finally, when employing the $\$ 5.50$ a day poverty line-i.e., the median value of the poverty lines among upper-middle-income countries-the relative incidence could rise for the first time since 1993, from 43.4 per cent in the status quo up to just above half of the world's population (50.6 percent) under a 20 per cent contraction. By this standard, the additional number of poor in comparison to the status quo could reach 124 to 527 million, depending on the contraction scenario (Table 2), thus moving the absolute incidence back to the levels recorded five to eight years ago.

Table 2. Absolute poverty incidence at $\$ 1.90, \$ 3.20$, and $\$ 5.50$ a day and changes under a 5,10 , and $20 \%$ per capita income/consumption contraction (millions of people)

\begin{tabular}{lcllrrr}
\hline \multirow{2}{*}{ Scenarios } & \multicolumn{3}{c}{ People living under } & \multicolumn{3}{c}{ Additional people living under } \\
\cline { 2 - 7 } & $\mathbf{\$ 1 . 9 0}$ & $\mathbf{\$ 3 . 2 0}$ & $\mathbf{\$ 5 . 5 0}$ & $\mathbf{\$ 1 . 9 0}$ & $\mathbf{\$ 3 . 2 0}$ & $\mathbf{\$ 5 . 5 0}$ \\
\hline Status quo & 727.3 & $1,819.5$ & $3,193.0$ & & & \\
\hline 5\% hit & 807.5 & $1,952.5$ & $3,317.5$ & 80.1 & 133.0 & 124.4 \\
10\% hit & 898.8 & $2,094.1$ & $3,443.7$ & 171.5 & 274.5 & 250.7 \\
20\% hit & $1,122.3$ & $2,395.5$ & $3,720.3$ & 395.0 & 576.0 & 527.2
\end{tabular}

Source: authors' estimates based on PovcalNet.

A further issue is that the worsening in people's livelihoods as a consequence of the crisis could result not only in a higher incidence of poverty but could also exacerbate both poverty intensity and severity. Table 3 illustrates that the latter measure, reflected by the squared average per capita poverty gap and typically interpreted as a measure of inequality among the poor, could increase in comparison to the status quo by as much as 60 per cent among the extreme poor under the worstcase scenario, and between 30 and 40 per cent for the higher poverty lines.

The poverty gap-defined in per capita terms to indicate the average shortfall in the income/consumption measure as a percentage of the poverty line-could register similar 
magnitudes of increase under a 20 per cent contraction, ranging between 30 and 60 per cent depending on the poverty line. The poverty gap is useful to reflect the total monetary cost to lift the income/consumption of the poor up to the value of the poverty line, and hence its worsening as a result of the crisis would imply a significant rise in such cost. This measure is often interpreted as the total amount of money needed to eradicate poverty according to the poverty line used, assuming a perfect allocation of resources among the poor and without including administrative costs. For instance, looking at the figures for the $\$ 1.90$ a day poverty line (Table 3), the average shortfall in income/consumption in the status quo is 3.2 per cent of the poverty line, or $\$ 0.06 \mathrm{a}$ day. Given a world population of 7.36 billion $^{12}$ the resources needed to lift the poor's incomes would amount to a total of $\$ 445.8$ million a day. Under a 20 per cent shock, a poverty gap of 5.1 per cent implies that such cost could therefore reach $\$ 707.4$ million a day, equivalent to an increase of 60 per cent in comparison to the status quo.

Table 3: Intensity and severity of poverty at $\$ 1.90, \$ 3.20$, and $\$ 5.50$ a day under a 5,10 , and $20 \%$ per capita income/consumption contraction (percentages)

\begin{tabular}{lrrrrrr}
\hline \multirow{2}{*}{ Scenarios } & \multicolumn{2}{c}{ Intensity (poverty gap) } & \multicolumn{3}{c}{ Severity (squared poverty gap) } \\
\cline { 2 - 7 } & $\mathbf{\$ 1 . 9 0}$ & $\mathbf{\$ 3 . 2 0}$ & $\mathbf{\$ 5 . 5 0}$ & $\mathbf{\$ 1 . 9 0}$ & $\mathbf{\$ 3 . 2 0}$ & $\mathbf{\$ 5 . 5 0}$ \\
\hline Status quo & 3.2 & 8.9 & 19.8 & 1.6 & 4.5 & 11.5 \\
\hline $5 \%$ hit & 3.5 & 9.8 & 21.0 & 1.7 & 5.0 & 12.3 \\
$10 \%$ hit & 4.0 & 10.7 & 22.3 & 1.9 & 5.6 & 13.3 \\
$20 \%$ hit & 5.1 & 12.9 & 25.3 & 2.5 & 6.9 & 15.5 \\
\hline
\end{tabular}

Notes: the intensity of poverty is measured by the per capita poverty gap, defined as the average shortfall in income/consumption (counting the non-poor as having zero shortfall) and expressed as a percentage of the poverty line. The severity of poverty is measured by the squared per capita poverty gap and can be interpreted as a measure of inequality among the poor, with a value of 100 indicating the maximum level of inequality. See Foster, Greer, and Thorbecke (1984) for further details on these measures.

Source: authors' estimates based on PovcalNet.

Next, we discuss the question how much welfare loss the existing and additional poor would experience. According to our estimates, a contraction of 5 per cent in individuals' welfare could imply a loss of $\$ 8$ million a day among those who would fall into extreme poverty. This relatively moderate loss could multiply by a factor of 4.5 if the contraction reaches 10 per cent. In the worstcase scenario, the income/consumption loss could drastically increase to almost $\$ 188$ million a day among the additional extreme poor, and to $\$ 461$ to 725 million a day ( $\$ 14$ to 22 billion per month) among the new poor at the higher poverty lines. ${ }^{13}$ These losses, summarised in the panel a of Figure 2, could be interpreted as the lower bound of a global economic compensation required to mitigate the adverse effects of the crisis only among the new poor. In other words, these estimates provide an indication of how much it would cost to bring levels of poverty back to what they were prior to the COVID-19 crisis.

Among the existing poor, the potential monetary cost derived from the contractions could amount to $\$ 73$ to $\$ 345$ million a day among the extreme poor, depending on the scenario, and up to $\$ 4.4$ billion a day for the highest poverty line and worst-case scenario (see panel b of Figure 2).

\footnotetext{
${ }^{12}$ Based on the aggregation of country-level total number of poor people using the extrapolated series for 2018 for 165 countries and for 2015 in the case of India.

${ }^{13}$ As noted, all monetary values are in international dollars at 2011 PPP exchange rates.
} 
Figure 2: Income/consumption losses among the new and existing poor under a 5, 10, and 20\% per capita contraction (\$ million a day)

a. Loss among the new poor

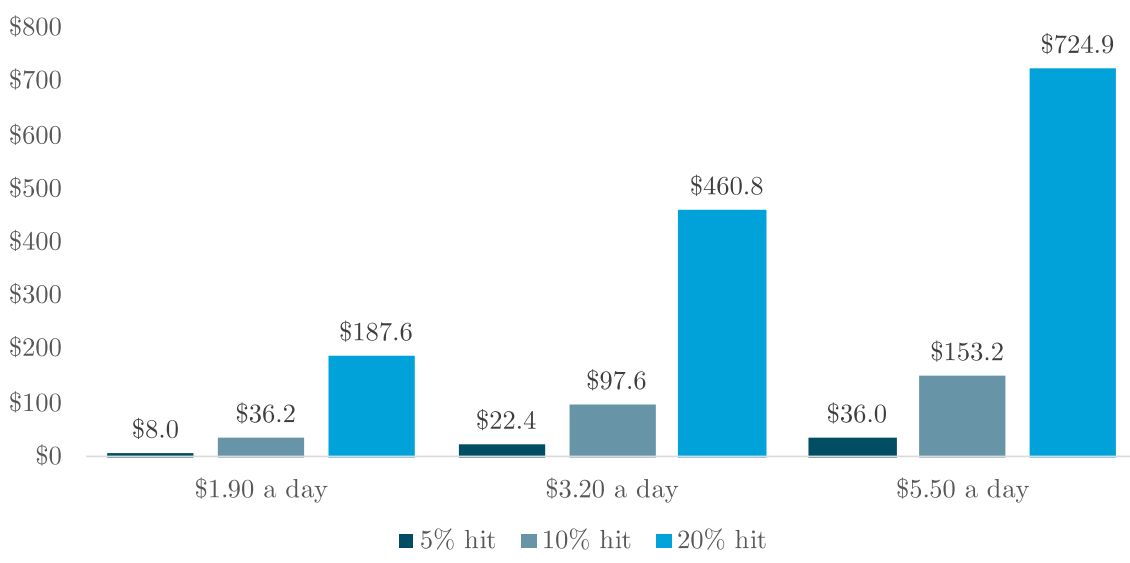

b. Loss among the existing poor

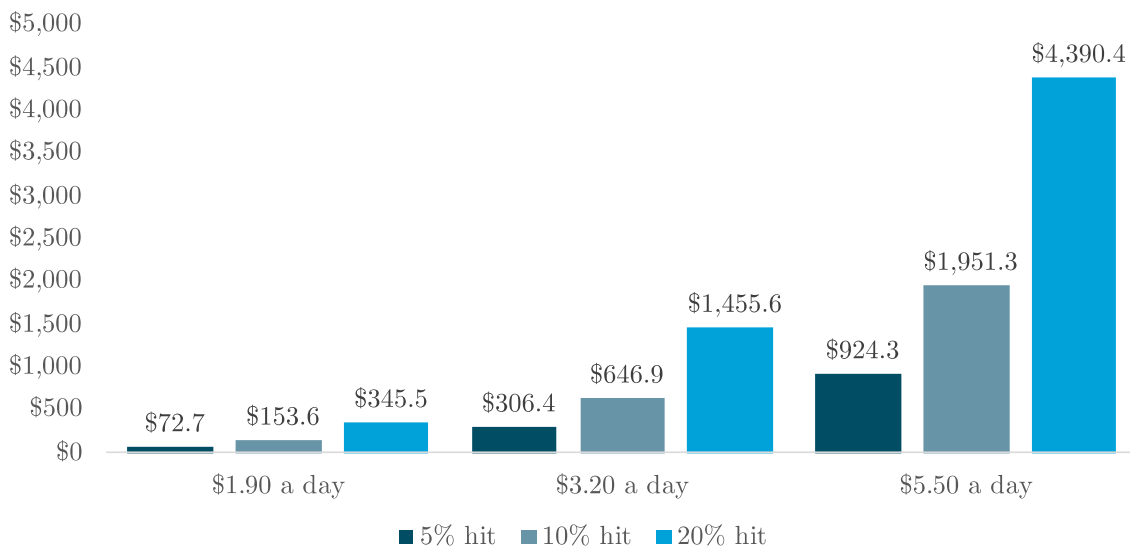

Source: authors' estimates based on PovcalNet.

\section{$4 \quad$ The changing distribution of global poverty}

Our contraction scenarios are, by design, applied equally across all countries. This implies that the potential short-term increase in poverty would be generalisable, although it could be especially marked in some regions compared to others depending on the poverty line utilised. The variation is due to the share of the population within each region that lives just above the poverty line. Figure 3 shows how the increase in poverty is distributed across six regions in the developing world. Based on the $\$ 1.90$ a day poverty line and a 20 per cent contraction, more than half of the 395 million additional extreme poor would be located in South Asia (SA), thus becoming the hardest hit region in the world-mainly driven by the weight of populous India-followed by SSA which would comprise 30 per cent, or 119 million, of the additional poor.

As the value of the poverty line increases, a larger share of the additional poor will be concentrated in regions where the corresponding poverty line is more relevant given the average income level. For instance, the regional distribution of the world's poor changes drastically when looking at the $\$ 5.50$ a day poverty line- the median poverty line among upper-middle-income countries. At this level, almost 41 per cent of the additional half a billion poor under a 20 per cent contraction scenario would live in East Asia and the Pacific (EAP), chiefly China; a fourth would still reside in 
SA; and a combined 18 per cent would live in the Middle East and North Africa (MENA) and in Latin America and the Caribbean (LAC), whose individual shares are close to that recorded for SSA ( 9.2 percent). This distribution of the additional number of poor is somewhat similar to that resulting from a 5 per cent or a 10 per cent contraction scenario.

Figure 3: Regional distribution of the additional number of poor at $\$ 1.90, \$ 3.20$, and $\$ 5.50$ a day under a 5,10 , and $20 \%$ per capita income/consumption contraction (percentages

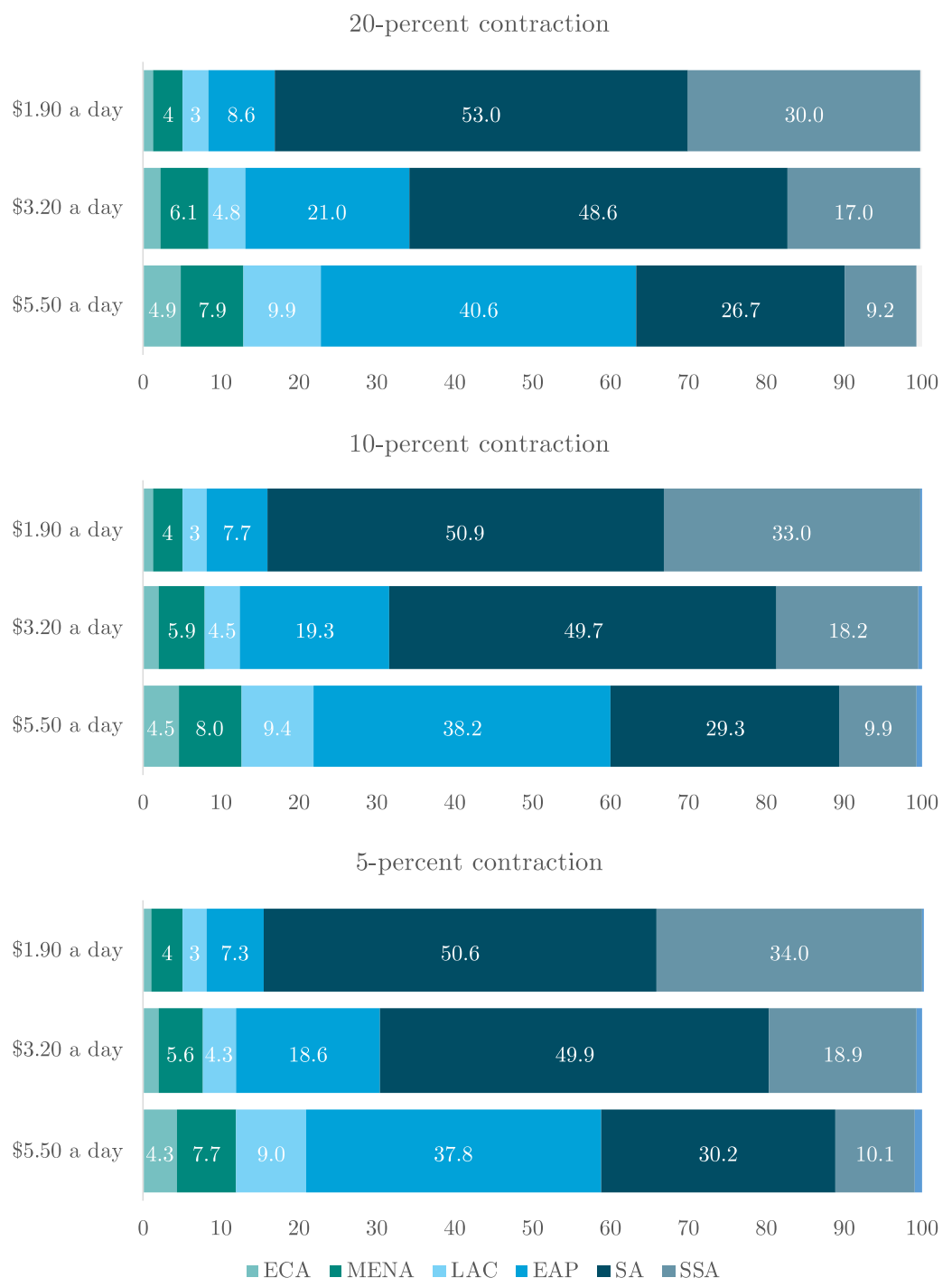

Notes: notice that the bars include a residual ranging $0.1-0.8 \%$, depending on the line. These shares correspond to the additional poor people living in a group of 28 advanced or high-income economies not included in the six developing regions (see the list of these countries under the label 'Other High Income' or OHI in Castañeda et al. 2019).

Source: authors' estimates based on PovcalNet.

How will the estimated increase in poverty affect past regional progress in poverty reduction? Figure 4 plots regions' absolute number of people living below the three poverty lines during 1990-2018, as well as our estimates under the contraction scenarios. The first notable finding is that in regions that previously experienced moderate to fast poverty reduction, the current crisis could lead to the first absolute increase in decades, regardless of the size of the per capita income/consumption contraction: in EAP, the number of poor could rise for the first time since 1990 at both the $\$ 1.90$ a day and $\$ 3.20$ a day poverty lines, and since 1999 at the highest poverty line; in SA, the potential increase would be the first recorded in the last two decades at the two 
lower poverty lines; and in LAC it would be the first rise since the early 2000s for all three poverty lines.

Figure 4: Regional poverty incidence at $\$ 1.90, \$ 3.20$, and $\$ 5.50$ a day; $1990-2018$ and estimates under a 5,10 , and $20 \%$ per capita income/consumption contraction (millions of poor)
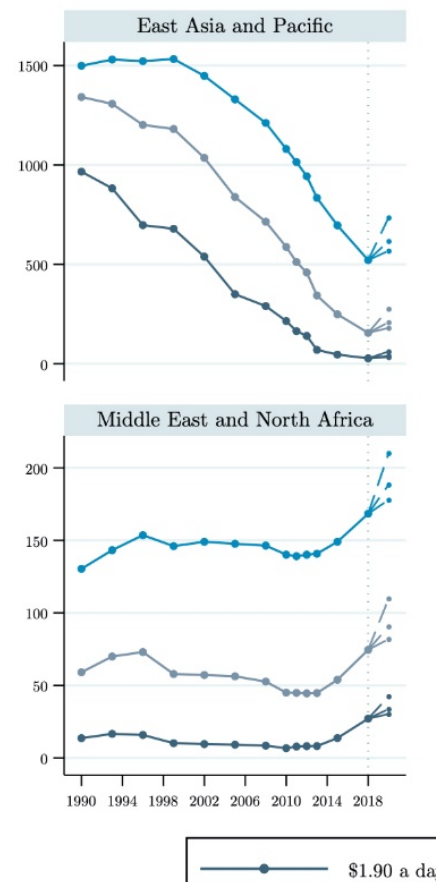
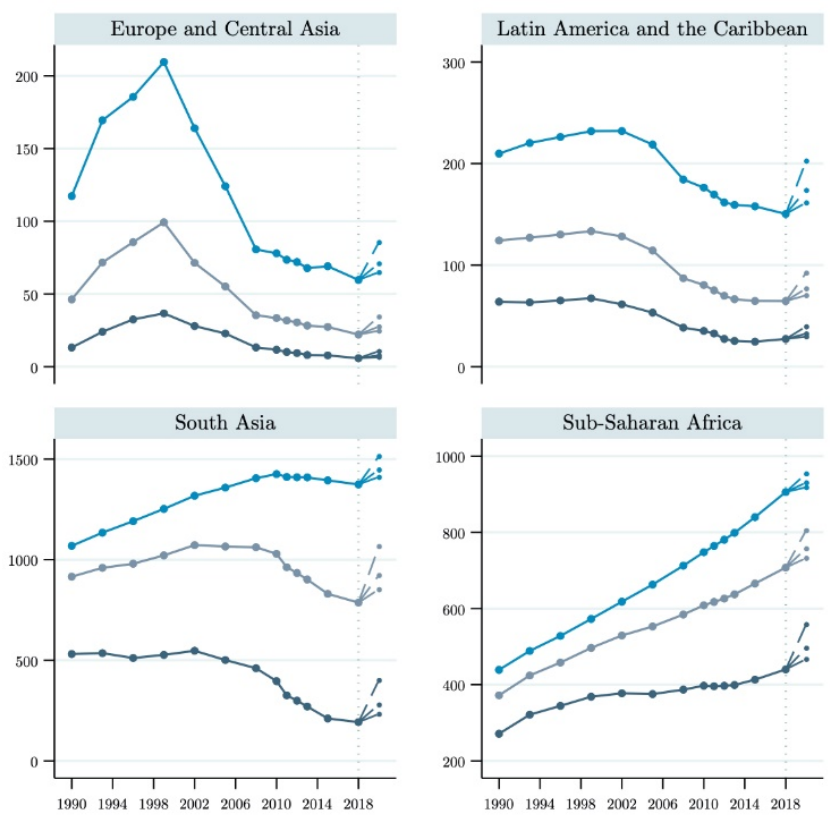

$\$ 5.50$ a day

Note: dashed lines after 2018 represent the estimated increase in the incidence of poverty for each poverty line under the income/consumption contraction scenarios, with the lower, middle, and upper dashed lines representing, respectively, the 5, 10, and 20 per cent contraction.

Source: authors' estimates based on PovcalNet.

A second finding is related to the magnitude of the reversal such increases would impose on the regions' progress in poverty reduction. In SA, a contraction of 10 per cent could erase the progress of the last eight years in reducing poverty at $\$ 1.90$ and $\$ 3.20$ a day, whilst a contraction of 20 per cent could potentially cause a return to the levels recorded in the second half of the 2000s. In LAC, a 10 per cent drop in per capita income/consumption may wipe out a decade of relatively slow progress in reducing $\$ 5.50$ a day poverty, whereas a 20 per cent drop could take its absolute incidence back to the 2005 level. A similar reversal of 10-15 years progress in reducing the incidence of $\$ 5.50$ a day poverty could also occur in Eastern Europe and Central Asia (ECA) under a 20 per cent shock, whilst in EAP the potential reversal may not be beyond the levels observed around five years ago. Finally, the absolute numbers of poor in 2018 in both MENA and SSA were already the highest recorded during the period under study, regardless of the poverty line used, so that even the lowest contraction of 5 per cent would set a new poverty high. These potential effects that the current COVID-19 crisis could leave on poverty look more dramatic when focusing on the composition of global poverty since 1990. Mainly as a result of three decades of accelerated and poverty-reducing economic expansion in China, the combined contribution of South Asia and SSA to global poverty at $\$ 1.90$ a day moved from 43 per cent in 1990 to 87 per cent in 2018-a contribution dominated by SSA since 2011 (see top of panel a of Figure 5). This latter proportion is equivalent to a combined 633 million people living in extreme poverty in those regions ahead of the pandemic. Under the assumption that per capita consumption drops by 5 per cent, such a figure would jump back to just above 700 million poor, which is close to the level recorded around 2012; if the shock is 10 per cent instead, then the total would reach almost 780 million, or close to 
that observed back in 2010; and, if the scenario of a 20 per cent contraction takes place, then the combined extreme poor in South Asia and SSA could be a startling new high of 960 million, or 86 per cent of the estimated 1.12 billion extreme poor globally-in SSA only, a contraction of this magnitude could push the current incidence to above half billion people.

We also consider the composition of global poverty by countries' income level. The graphs in panel $\mathrm{b}$ of Figure 5 show the dramatic potential exacerbation of extreme poverty especially in middle-income countries. Focusing on extreme poverty, the adverse consumption effects due to the lockdown during the pandemic could erase the impressive reduction in the incidence in today's lower-middle-income countries achieved since 1999 by at least a decade, pushing the pre-crisis number of poor upwards from 388 million up to 680 million people under the worst-case scenario. The absolute incidence of extreme poverty in 2018 among currently classified low-income countries (291 million poor) was already the highest recorded during the analysed period and was about 55 per cent higher than the incidence observed back in 1990 (187 million poor).

Figure 5. Composition of the global poverty incidence at $\$ 1.90, \$ 3.20$ and $\$ 5.50$ a day: $1990-2018$ and estimates under a 5,10 , and $20 \%$ per capita income/consumption contraction (millions of poor)
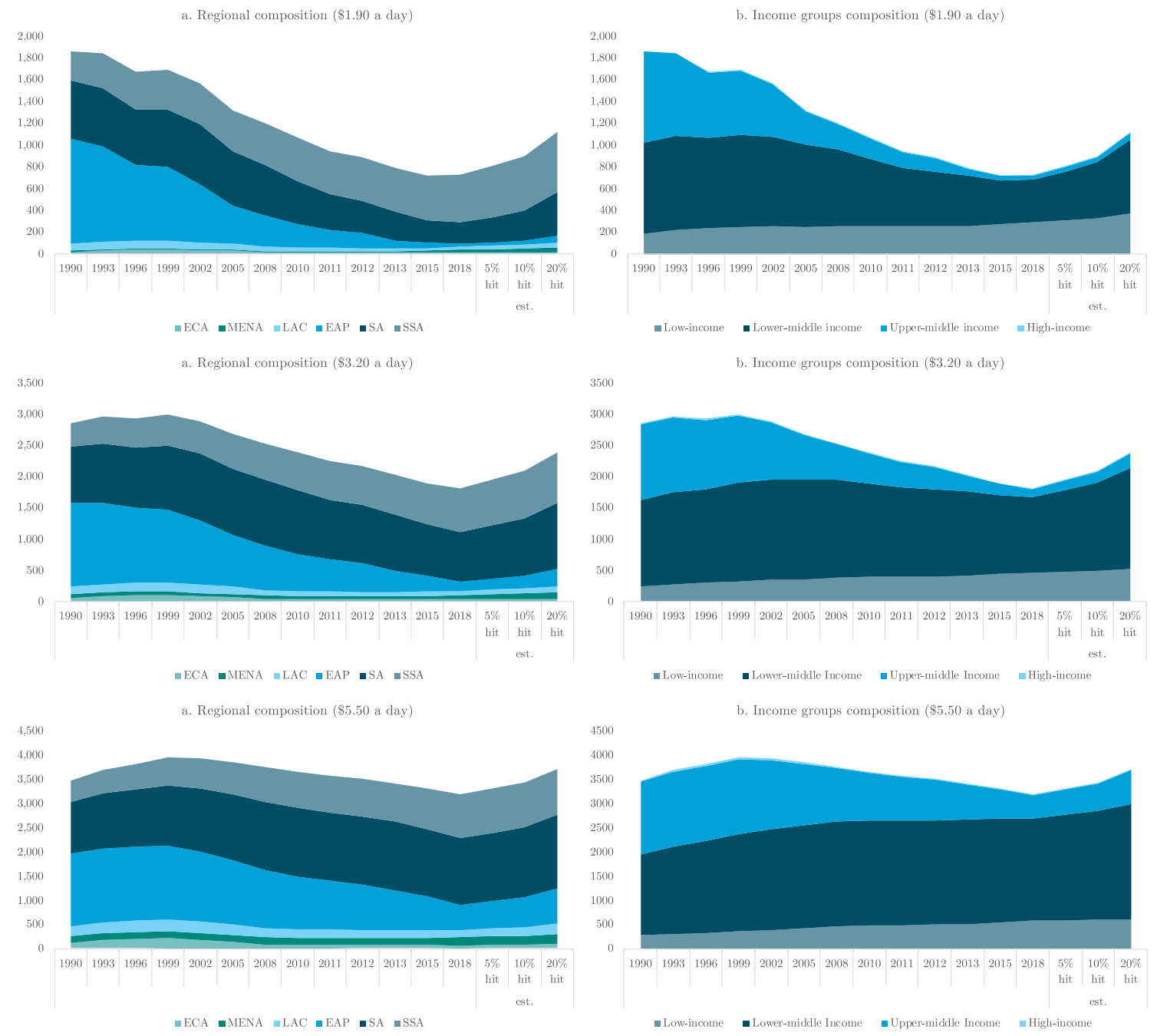

Source: authors' estimates based on PovcalNet.

\section{The pandemic's new poor: country-level estimates}


India plays a significant role in driving the potential increases in global extreme poverty documented previously, comprising almost half the estimated additional poor regardless of the contraction scenario (Figure 6). Nonetheless, there are other populous, low- and lower-middleincome countries in SA, SSA, and EAP accounting for a sizeable share of the estimates: Nigeria, Ethiopia, Bangladesh, and Indonesia come next, in that order, concentrating a total of 18-19 per cent of the new poor, whereas the Democratic Republic of Congo (DR Congo), Tanzania, Pakistan, Kenya, Uganda, and the Philippines could jointly add 11-12 per cent. Taken together, these figures imply that three quarters of the additional extreme poor globally could be living in just ten populous countries. ${ }^{14}$

Figure 6: Top contributors to global poverty at $\$ 1.90$ a day under a 5,10 , and $20 \%$ per capita income/consumption contraction (millions of poor)

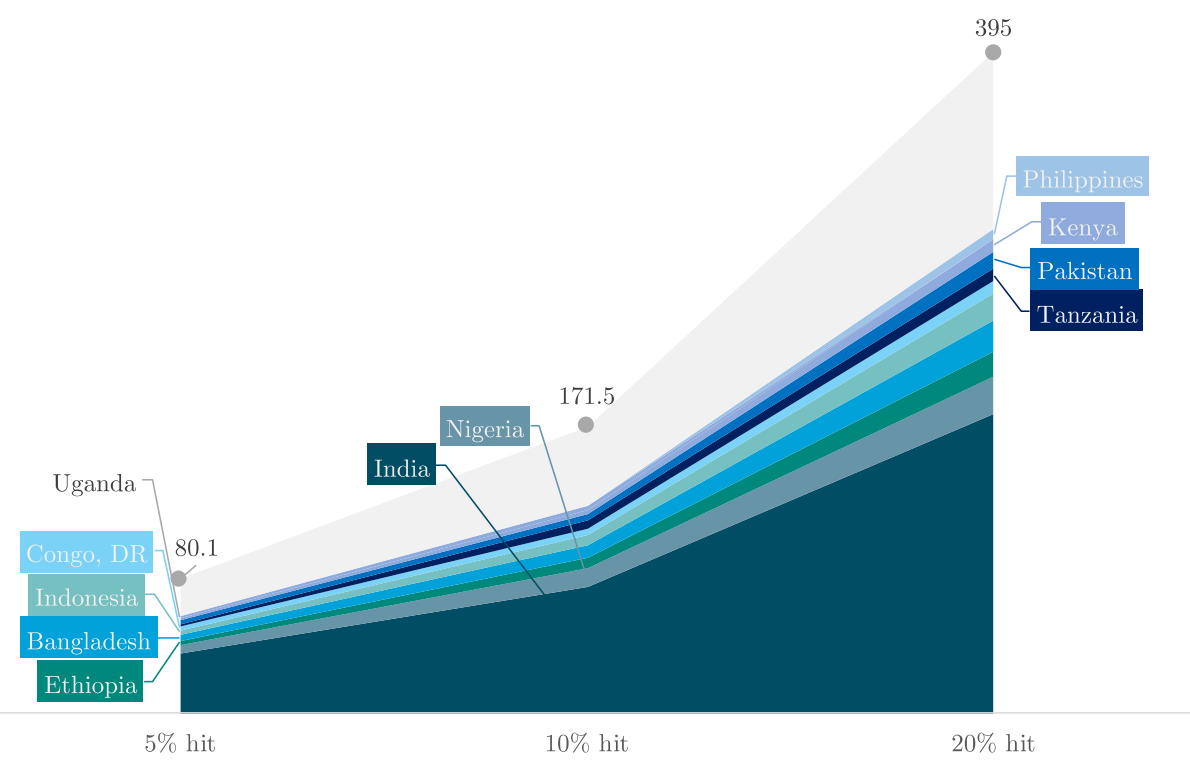

Source: authors' estimates based on PovcalNet.

This high concentration of the additional extreme poor is staggering, although not necessarily unexpected given the size of each country's population. Yet, these results are significant for at least two reasons. On one hand, the PovcalNet dataset shows that three of these ten countries (Ethiopia, India, and Nigeria) were among the top ten by number of extreme poor people in 1990 and remained within the ranks of that group until 2018. Despite this crude fact, two of these countries have managed to achieve a sustained reduction in their incidence of poverty since the early 1990s, namely Ethiopia and India, reaching their lowest poverty headcount ratio ever recorded at about 22 and 13 per cent, respectively (panel a of Figure 7). Nonetheless, the potential contraction in per capita income/consumption imposed by the pandemic's economic effects could erase some of this progress.

Three countries, namely Bangladesh, Indonesia, and Pakistan, were also among the top ten by number of poor in 1990. However, over the course of almost three decades Bangladesh has pushed its extreme poverty headcount ratio from 38.5 per cent to 7.8 per cent, whereas Indonesia and

\footnotetext{
${ }^{14}$ Figure 6 plots the contributions of 11 countries. Uganda, but not the Philippines, could be among the top ten contributors to additional global poverty under the 5 and 10 per cent contraction scenarios. Conversely, the Philippines, but not Uganda, could be among the top ten when considering a contraction of 20 per cent in per capita income/consumption. Table A 3 in the annex presents the absolute numbers for the top 25 countries by number of additional poor.
} 
Pakistan did so from levels close to 60 per cent to 4.6 and 1.6 per cent, respectively (panel b of Figure 7).

Figure 7: Poverty headcount ratios at $\$ 1.90$ and $\$ 3.20$ a day in selected top contributors to additional global poverty; 1990-2018 and estimates under a 5, 10, and 20\% per capita income/consumption contraction (\% of country's population)

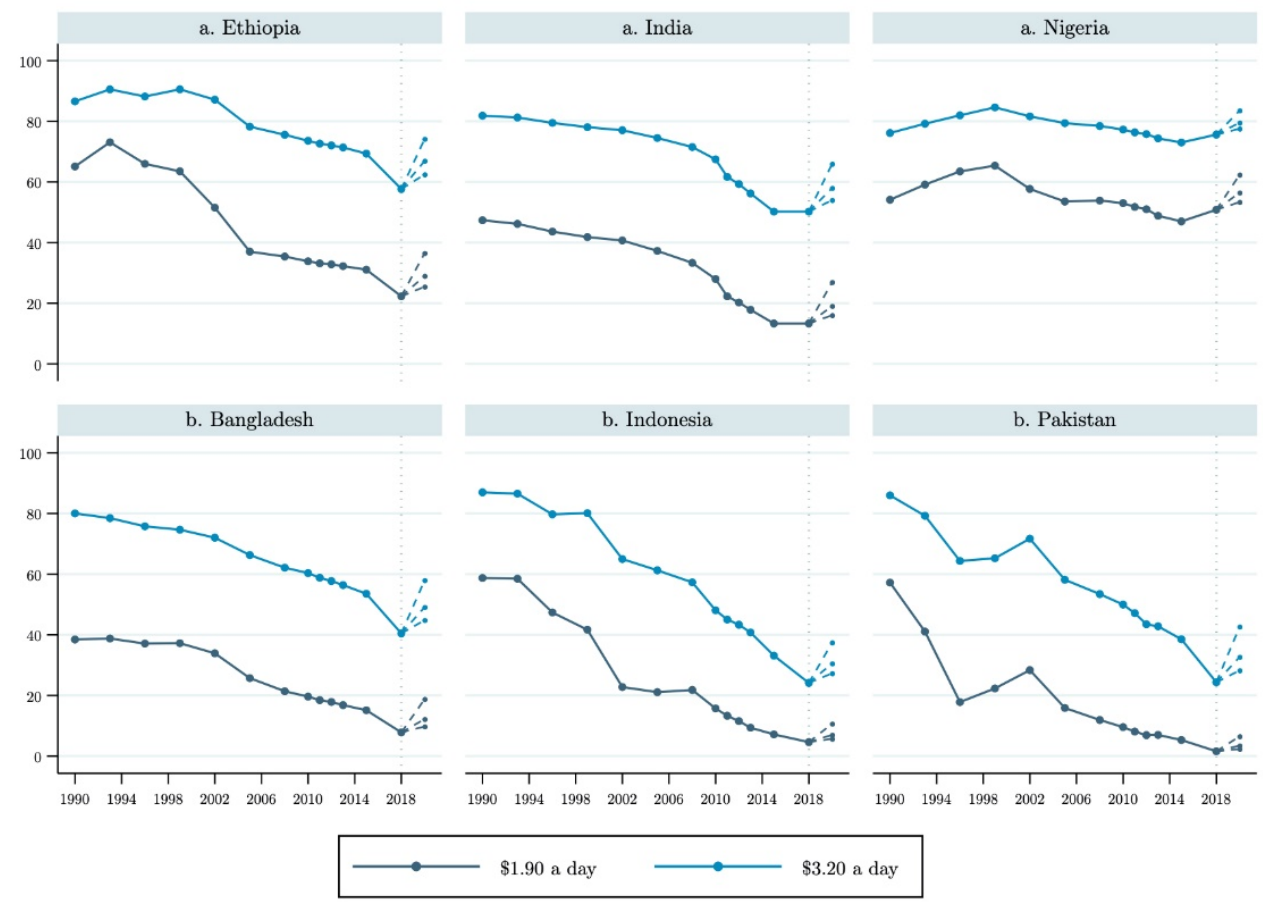

Note: dashed lines after 2018 represent the estimates increase in the incidence of poverty for each poverty line under the income/consumption contraction scenarios, with the lower, middle, and upper dashed lines representing, respectively, the 5,10 , and 20 per cent contraction.

Source: authors' estimates based on PovcalNet.

The possibility that these countries concentrate a significant share of the new poor as a result of the current COVID-19 crisis points not only to their population size (ranging between 160-270 million), but also suggests that much of their previously poor citizens moved just above the $\$ 1.90$ a day poverty line, thus remaining in a position of high vulnerability to poverty in the face of shocks. The risk that a sizeable share of near poor could fall into poverty following a per capita income/consumption contraction is particularly distinct when looking at $\$ 3.20$ a day povertywhich seems a more appropriate standard given that these countries' average welfare levels position all of them within the group of current lower-middle-income economies.

The remaining countries that could be among the top contributors of additional extreme poverty globally, namely DR Congo, Tanzania, Kenya, the Philippines, and Uganda, were not among the top ten by number of extreme poor back in 1990, although they all were teetering on the verge of joining that group. This risk eventually materialised by 2018 for four of them as a result of their poverty headcount ratios remaining high and relatively stagnant, particularly so in DR Congo and Kenya (panel a of Figure 8), while previously poorest, fast-growing economies in EAP such as China, Myanmar, and Vietnam were recording major poverty reduction (panel b of Figure 8). ${ }^{15}$

${ }^{15}$ As shown in Figure 8, the poverty headcount ratio in both China and Vietnam declined from above 60 per cent in 1990 to, respectively, 0.3 and 1.9 per cent in 2018, whereas in Myanmar the ratio moved from almost 96 per cent to just below two per cent. These results are partially the consequence of the economic expansion these countries experienced, with their GDP per capita growing at an average annual rate of above eight per cent in both China and 
The only exception is the Philippines which, although far from the current group of the ten poorest countries and with an extreme poverty headcount ratio reaching a record low of 4.6 per cent in 2018 , could add above six million new poor to the global count. This estimate again points to a sizeable share of the non-poor population living just above the poverty line and suggests that recent progress in the Philippines as well as in other countries has been relatively fragile.

Figure 8: Poverty headcount ratios at $\$ 1.90$ and $\$ 3.20$ a day in selected top contributors to additional global poverty (panel a) and selected top ten poorest countries in 1990 (panel b); 1990-2018 and estimates under a 5, 10 , and $20 \%$ per capita income/consumption contraction ( $\%$ of country's population)
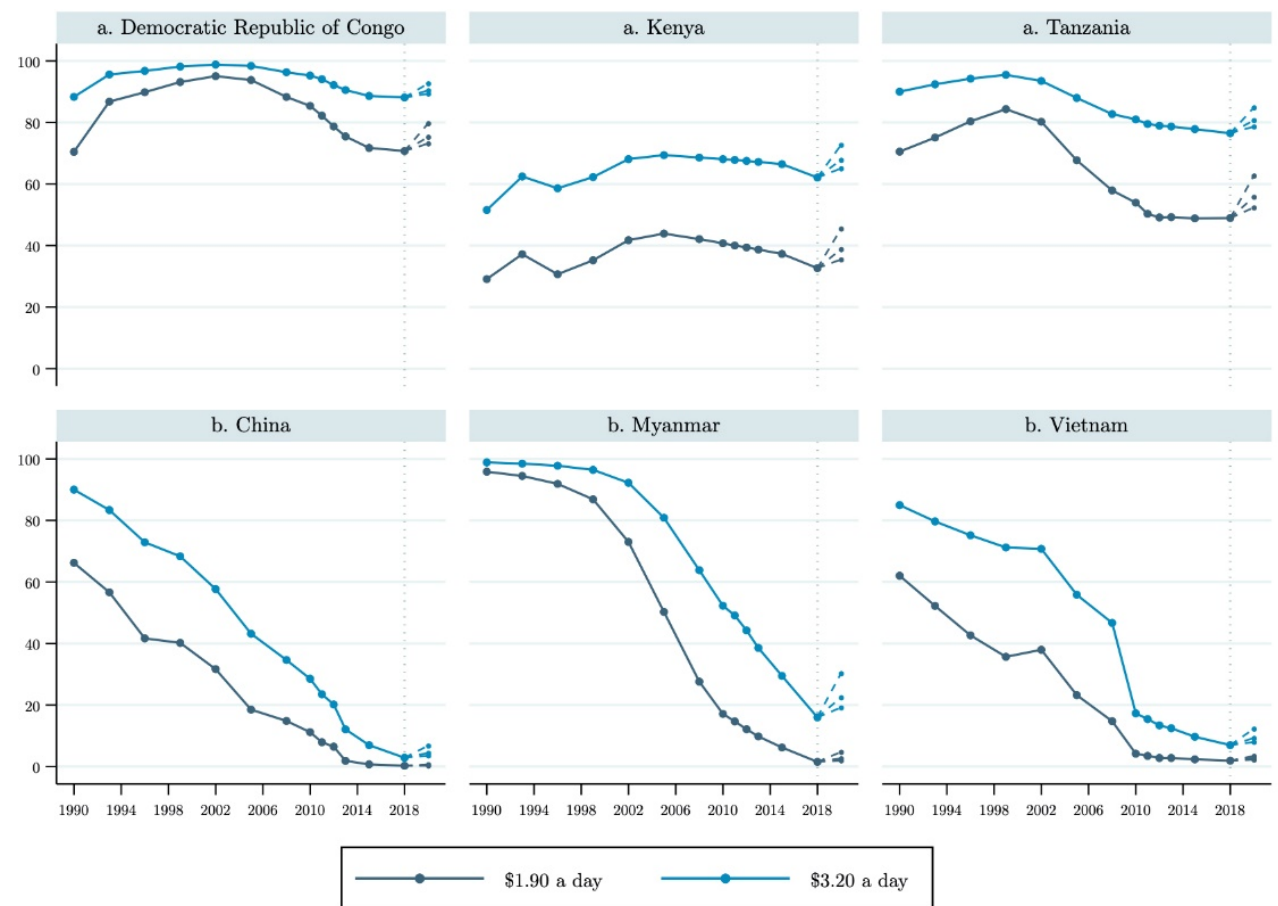

Note: dashed lines after 2018 represent the estimated increase in the incidence of poverty for each poverty line under the income/consumption contraction scenarios, with the lower, middle, and upper dashed lines representing, respectively, the 5,10 , and 20 per cent contraction.

Source: authors' estimates based on PovcalNet.

Finally, and as noted in the previous section, as the standard to quantify the incidence of poverty increases in value, the additional poor as a result of the current crisis will tend to be concentrated in populous places where the average per capita welfare is higher. For instance, moving to the other end of spectrum, when measuring poverty by the median poverty line among upper-middleincome economies, i.e., at $\$ 5.50$ a day, the data reveal that Bangladesh, India, Indonesia, Pakistan, and the Philippines would remain among the top ten contributors of additional poverty to the global count, together accounting for more than a third of the total new poor across the different contraction scenarios. At this highest poverty line, however, five other large countries in EAP, MENA, and LAC could play a significant role by contributing an additional third of the new global poor. These ten countries would comprise about 70 per cent of the total new poor regardless of the contraction scenario, with the lion's share accruing in both China and India (respectively, those two countries could be driving a fourth and a fifth of the potential increase in the absolute number of poor globally).

Myanmar, and 5.3 per cent in Vietnam. These three countries, plus Brazil, complete the top ten poorest countries in 1990 by number of poor. 
Figure 9. Top contributors to global poverty at $\$ 3.20$ and $\$ 5.50$ a day under a 5,10 , and $20 \%$ per capita income/consumption contraction (millions of poor)
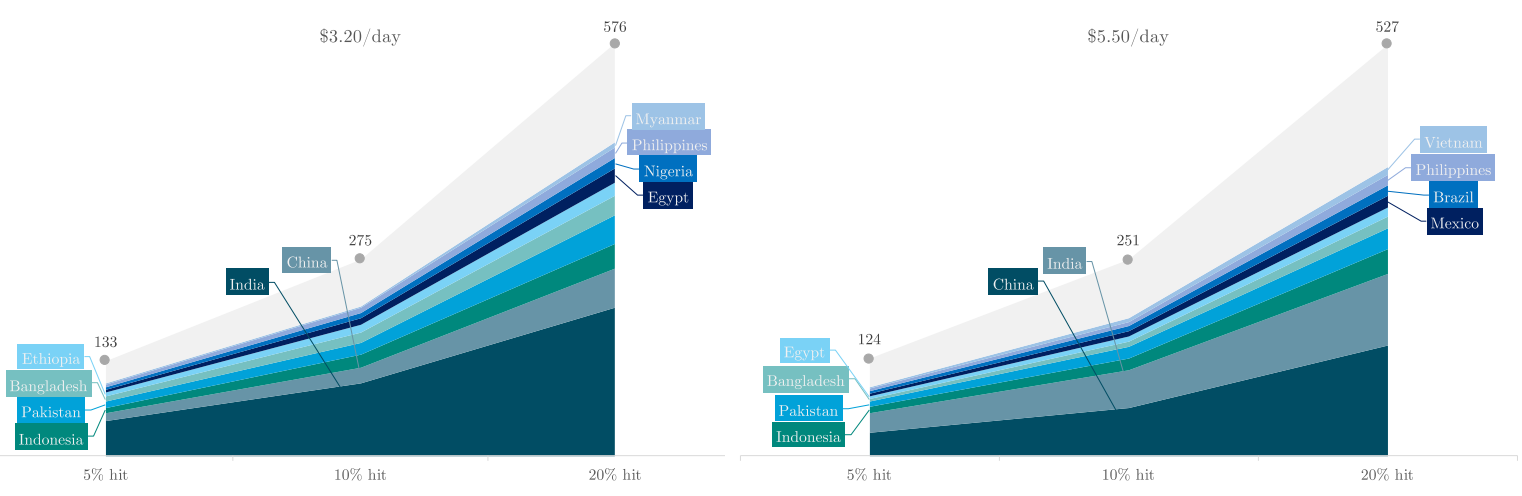

Source: authors' estimates based on PovcalNet.

Figure 10: Top 20 largest increases in poverty headcount ratios at $\$ 1.90, \$ 3.20$, and $\$ 5.50$ a day under a 5, 10, and $20 \%$ per capita income/consumption contraction (percentage points)

$\$ 1.90$ a day poverty line
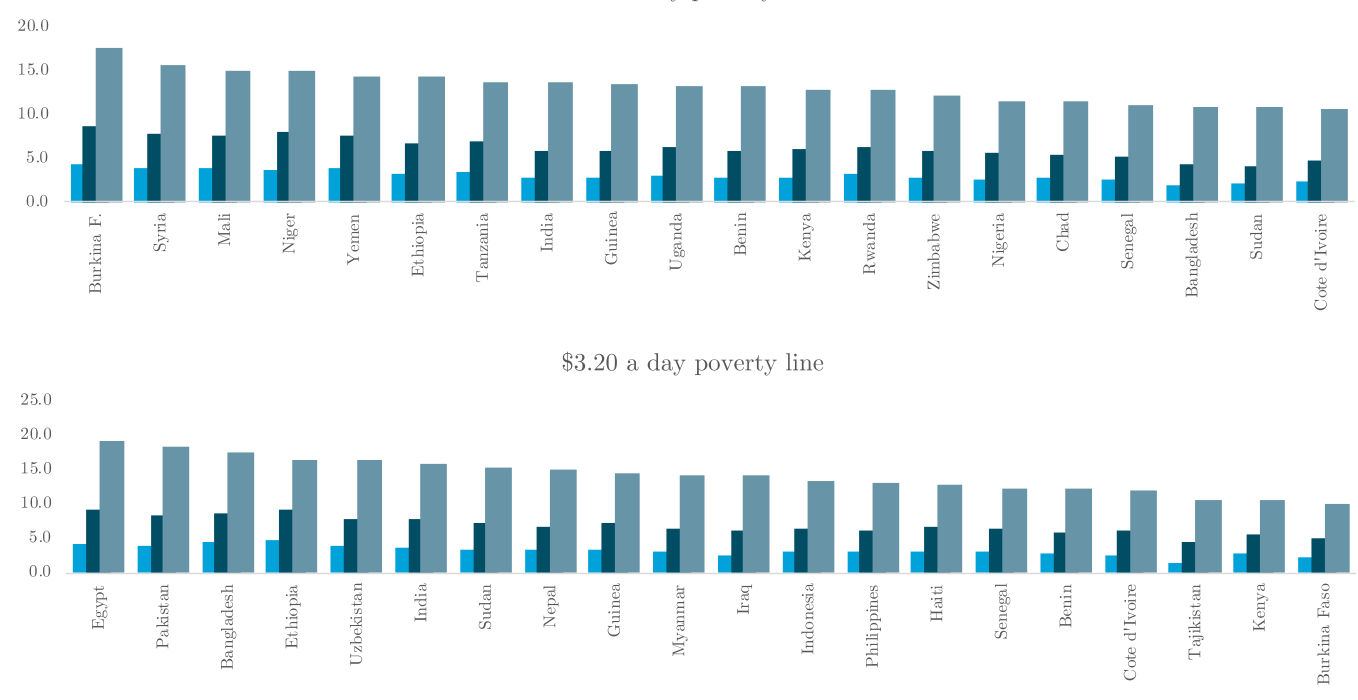

$\$ 5.50$ a day poverty line

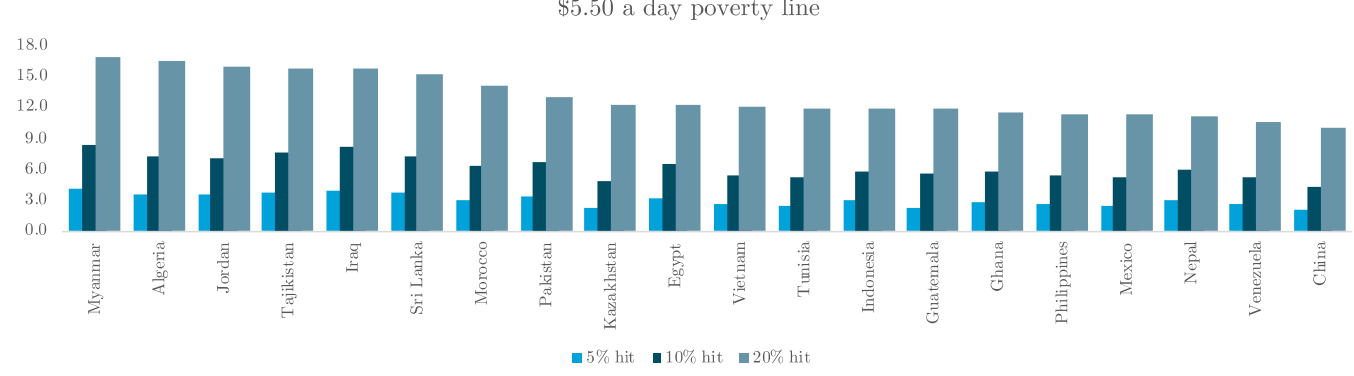

Source: authors' estimates based on PovcalNet.

Looking at the potential increases in terms of percentage points, relative to the poverty headcount ratio in the status quo, and restricted to countries with a population of at least 10 million, Figure 10 shows that the increase could average at startlingly 13 percentage points under a 20 per cent shock, and between three to six points for the lower contraction scenarios-regardless of the poverty line used. Some already familiar patterns become evident again: many increases would occur in low-income countries in SSA when looking at $\$ 1.90$ a day, but as the value of the poverty line increases the larger impacts would occur among middle-income countries and more evenly across regions. Figure 11 illustrates the change in the poverty headcount ratio (in percentage 
points) versus the poverty headcount ratio of the status quo. Our estimates show that the effects of each contraction scenario are not linear with the poverty headcount ratios prior to the COVID19 crisis - that is, the developing countries with smaller or larger amounts of poverty in the status quo are relatively less impacted in percentage points, thus suggesting relatively worse outcomes among lower-middle-income countries and pointing to the fragility of the progress they achieved at each poverty line.

Figure 11: Change in poverty headcount ratio (percentage points) versus poverty headcount ratio in the status quo

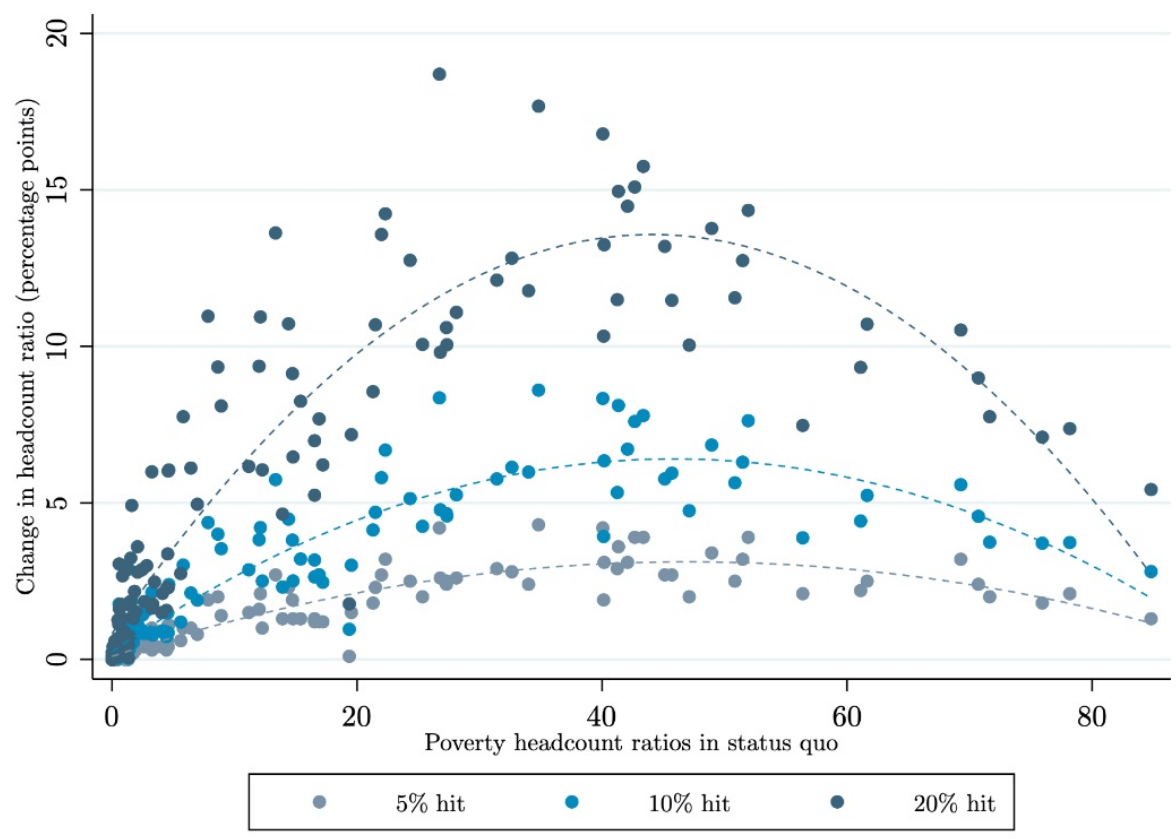

Source: authors' estimates based on PovcalNet.

\section{Conclusions}

In this paper we presented estimates of the potential short-term impact of COVID-19 on both the levels of monetary-based poverty in developing countries and the composition of global poverty. The estimates are implicitly focused on precarity due to our augmented poverty line approach (using the World Bank's international poverty lines of $\$ 1.90, \$ 3.20$, and $\$ 5.50$ a day). Our estimates are based on scenarios of the potential contraction in per capita income or consumption that could result from the lockdown measures undoubtedly necessary to keep the spread of the COVID-19 under control, but which at the same time could exert pernicious effects on the livelihoods of parts of the population whose income-generating capacities are restricted. These effects could furthermore interact with pre-existing conditions of fragmented or insufficient social protection systems.

Our contraction scenarios range from 5 to 20 per cent, in line with a set of short-term projections. The estimated effects on poverty rates are intended to be indicative of a range in magnitude, not predictions, of the potential increases in poverty. By being distribution-neutral and static, our estimates omit household-level responses to said contractions, as well as labour market, social assistance, and fiscal policy channels. Our estimates thus have important limitations. The real poverty impacts ultimately will be determined by the precise per capita welfare shock in each country, the duration of the crisis, and governments' abilities to mitigate. 
Three main findings are worth highlighting. First, depending on the extent of the economic shock from COVID-19, our estimates suggest that 80-395 million people could fall into extreme poverty globally, whereas this number rises to $124-527$ million people when considering the highest poverty line of $\$ 5.50$ a day. The potential increase in extreme poverty could mark the first absolute increase in the global count since 1999_and the first since 1990 in terms of the headcount ratio.

Secondly, we show there could be not only an increased incidence of global poverty, but crucially the intensity and severity of poverty is likely to rapidly increase. The resources needed to lift the incomes of the poor to the poverty lines, as indicated by the poverty gap, could increase by 60 per cent, from $\$ 446$ million a day in the absence of crisis to above $\$ 700$ million a day under a 20 percent contraction. In most of our scenarios the global consumption shortfall is in excess of $\$ 100$ million a day.

Third, our estimates show that poverty is likely to increase dramatically in middle-income developing countries and there could be a significant change in the distribution of global poverty. There could be much more new poverty not only in countries where poverty has remained relatively high over the last three decades and also in countries that are not among the poorest anymore, which points not only to their population size, but also suggests that much of their previously poor people moved to just above the poverty line, thus implying that the recent progress they achieved has been relatively fragile.

One important question our findings raise is whether the economic impact will be as significant for poverty effects as the health-related aspects of the pandemic. As developing countries generally have a lower proportion of people at higher risk in terms of age ( $>70$ years), the economic shock may be more significant. However, that said health systems in developing countries tend to be weaker than those of advanced ones. Furthermore, higher COVID-19 morbidity and mortality rates have been linked to hypertension and diabetes as well as to poverty, pollution, and malnutrition, which could make populations of developing countries more vulnerable to the COVID-19 disease (see, for instance, Schellekens and Sourrouille, 2020). There are also unclear links between COVID-19 and other illnesses such as TB, HIV/AIDS, chronic malaria, and respiratory problems due to indoor cooking. Nevertheless, the question emerges whether a lockdown is the only option to contain the virus if the lockdown entails an income loss and whether a lockdown would even be feasible in high density urban areas or when it causes people to remain without income and thus without food. Dingel and Neiman (2020) estimate that the share of jobs that could be performed at home is less than 25 per cent for the bulk of developing countries-much lower than the above 40 figure recorded, for instance, in the US or Finlandand as low as five per cent in countries such as Madagascar and Mozambique. Consequently, there is a clear need for a range of social safety net policies which already exist in many developing countries but whose coverage and funding needs to be expanded substantially as part of 'pay-tostay home' or 'pay-to-test' schemes.

Looking further ahead, the poverty impacts beyond 2020 are closely related to if or when a vaccine is developed, how effective it is, who gets the vaccine and who does not (eventually culminating in the question of who pays), and the time needed to roll out the vaccine. It is unlikely that the crisis will end completely within 2020 and, conversely, very likely that the pandemic will proceed in multiple waves. Currently, there are no vaccines available for any corona viruses, neither is there an absolute guarantee of immunity after an infection. So, what if no vaccine against COVID-19 is found or if it is less than 100 per cent effective? Even if we take the best-case scenario and a vaccine could be discovered in two years' time, it could take some yet uncertain amount of time for it to be rolled out and to reach the entire global population. And even if a vaccine is developed, there is no guarantee everyone would get it for free. Will we end up living in a new COVID-19 apartheid with the vaccinated and non-vaccinated residing in separate areas and working in 
different labour markets? While this might sound far off, already now there are some countries issuing 'immunity passports'.

In conclusion, although in this paper we have focused on the short-term economic impacts of the COVID crisis on poverty, the wider crisis will likely cause repercussions for global poverty for years to come.

\section{References}

Alkire, S., J. Dirksen, R. Nogales, and C. Oldiges (2020). 'Multidimensional Poverty and COVID-19 Risk Factors: A Rapid Overview of Interlinked Deprivations across 5.7 Billion People'. OPHI Briefing 53. Oxford Poverty and Human Development Initiative (OPHI), Oxford: University of Oxford.

Asian Development Bank (ADB) (2020). 'Updated Assessment of the Potential Economic Impact of COVID-19'. ADB Briefs. Manila: ADB.

Atamanov, A., C. Lakner, D.G. Mahler, S.K. Tetteh Baah and J. Yang (2020). 'The Effect of New PPP Estimates on Global Poverty: A First Look'. Global Poverty Monitoring Technical Note, 12. Washington DC: World Bank.

Castañeda Aguilar, R.A., C. Lakner, E.B. Prydz, J. Soler Lopez, R. Wu, and Q. Zhao (2019). 'Estimating Global Poverty in Stata. The PovcalNet Command'. Global Poverty Monitoring Technical Note 9. Washington DC: World Bank. https://doi.org/10.1596/32477

Dingel, J., and B. Neiman (2020). 'How Many Jobs Can be Done at Home?'. COVID Economics, Vetted and Real Time Papers, (1): 16-24.

Felman, J., J. Sandefur, A. Subramanian, and J. Duggan (2019). 'Is India's Consumption Really Falling?'. Center for Global Development blog. Washington DC: Center for Global Development.

Foster, J., J. Greer, and E. Thorbecke (1984). 'A Class of Decomposable Poverty Measures'. Econometrica, 52(3): 761-66. https://doi.org/10.2307/1913475

Gentilini, U., M. Almenfi, P. Dale, J. Blomquist, R. Palacios, V. Desai, and V. Moreira (2020). 'Social Protection and Jobs Responses to COVID-19: A Real-Time Review of Country Measures'. Living Paper, version 9, 15 May. Washington DC: World Bank.

Hatayama, M., M. Viollaz, and H. Winkler. (2020). 'Jobs' Amenability to Working from Home Evidence from Skills Surveys for 53 Countries'. Policy Research Working Paper, 924. Washington DC: World Bank.

International Labour Organization (2018). Women and Men in the Informal Economy: A Statistical Picture. Third edition. Geneva: ILO.

International Labour Organization (2020a). 'COVID-19 and the World of Work: Impact and Policy Responses’. ILO Monitor, first edition. Geneva: ILO.

International Labour Organization (2020b). 'COVID-19 and the World of Work: Updated estimates and analysis'. ILO Monitor, third edition. Geneva: ILO.

International Monetary Fund (2020). 'The Great Lockdown'. World Economic Outlook, April 2020. Washington DC: IMF.

Jolliffe, D., and E.B. Prydz (2016). 'Estimating International Poverty Lines from Comparable National Thresholds'. Journal of Economic Inequality, 14(2): 185-98. https://doi.org/10.1007/s10888-0169327-5

Kissler, S.M., C. Tedijanto, E. Goldstein, Y.H. Grad, and M. Lipsitch (2020). 'Projecting the Transmission Dynamics of SARS-CoV-2 through the Post-pandemic Period'. Science, 368(6493): 860-8. https://doi.org/10.1126/science.abb5793 
Laborde, D., W. Martin and R. Vos (2020). 'Poverty and Food Insecurity Could Grow Dramatically as COVID-19 Spreads’. 16 April. International Food Policy Research Institute Blog.

Lea, N. (2020). The Impact of COVID-19 on Extreme Poverty. London: Chief Economist's Office, Department for International Development.

Mahler, D.G., C. Lakner, R.A. Castañeda Aguilar, and H. Wu (2020). 'The impact of COVID-19 (Coronavirus) on Global Poverty: Why Sub-Saharan Africa might be the Region Hardest Hit'. World Bank Blog. Washington DC: World Bank.

McKibbin, W., and R. Fernando (2020). The Global Macroeconomic Impacts of COVID-19: Seven Scenarios. Washington DC: Brookings Institution.

Organisation for Economic Co-Operation and Development (2020). Evaluating the initial impact of COVID19 containment measures on economic activity. Paris: OECD.

Packard, T., U. Gentilini, M. Grosh, P. O'Keefe, R. Palacios, D. Robalino, and I. Santos (2019). Protecting All: Risk Sharing for a Diverse and Diversifying World of Work, Washington DC: World Bank. https://doi.org/10.1596/978-1-4648-1427-3

Sandefur, J., and Subramanian, A. (2020). 'The IMF's Growth Forecasts for Poor Countries Don't Match Its COVID Narrative'. CGD Working Paper 533. Washington DC: Center for Global Development.

Schellekens, P., and D. Sourrouille (2020). Tracking COVID-19 as Cause of Death: Global Estimates of Relative Severity. Washington DC: Brookings Institution.

Sumner, A., C. Hoy, and E. Ortiz-Juarez (2020). 'Estimates of the Impact of COVID-19 on Global Poverty'. WIDER Working Paper 2020/43. Helsinki: UNU-WIDER. https://doi.org/10.35188/UNU-WIDER/2020/800-9

United Nations (2020). World Economic Situation and Prospects as of mid-2020. New York: UN.

United Nations Development Programme (2020). 'COVID-19 and Human Development: Assessing the Crisis, Envisioning the Recovery'. 2020 Human Development Perspectives. New York: UNDP.

Valensisi, G. (2020) 'COVID-19 and Global Poverty: Are LDCs Being Left Behind?'. WIDER Working Paper 2020/73. Helsinki: UNU-WIDER. https:// doi.org/10.35188/UNU-WIDER/2020/830-6

Vos, R., W. Martin, and D. Laborde (2020a). 'As COVID-19 Spreads, No Major Concern for Global Food Security Yet'. International Food Policy Research Institute Blog, 10 march. Washington, DC: IFPRI.

Vos, R., W. Martin, and D. Laborde (2020b). 'How Much will Global Poverty Increase because of COVID19?'. International Food Policy Research Institute Blog, 20 march. Washington, DC: IFPRI.

World Bank (2020). East Asia and Pacific in the Time of COVID-19. Update April 2020. Washington DC: World Bank. https://doi.org/10.1596/978-1-4648-1565-2 


\section{Annex}

Table A1: Incidence of poverty by region and world total; 2018 and estimates under scenarios of contraction in per capita income/consumption (\% of population and millions of poor)

\begin{tabular}{|c|c|c|c|c|c|c|c|}
\hline \multirow{3}{*}{ Aggregate } & \multirow{3}{*}{ Population } & \multicolumn{6}{|c|}{ Headcount - status quo, 2018} \\
\hline & & \multicolumn{2}{|c|}{$\$ 1.90$ a day } & \multicolumn{2}{|c|}{$\$ 3.20$ a day } & \multicolumn{2}{|c|}{$\$ 5.50$ a day } \\
\hline & & $\%$ & Mill. & $\%$ & Mill. & $\%$ & Mill. \\
\hline East Asia and Pacific & $2,039.7$ & 1.3 & 27.3 & 7.6 & 155.5 & 25.6 & 521.3 \\
\hline Europe and Central Asia & 493.8 & 1.2 & 5.9 & 4.5 & 22.1 & 12.1 & 59.7 \\
\hline Latin America and the Caribbea & 621.5 & 4.4 & 27.3 & 10.4 & 64.7 & 24.2 & 150.5 \\
\hline Middle East and North Africa & 376.2 & 7.2 & 27.0 & 19.8 & 74.5 & 44.8 & 168.4 \\
\hline Other high Income & $1,034.4$ & 0.7 & 7.0 & 0.8 & 8.4 & 1.3 & 13.1 \\
\hline South Asia & $1,734.8$ & 11.1 & 192.7 & 45.4 & 786.7 & 79.2 & $1,374.1$ \\
\hline Sub-Saharan Africa & $1,058.5$ & 41.6 & 440.2 & 66.8 & 707.6 & 85.6 & 905.9 \\
\hline \multirow[t]{2}{*}{ World Total } & $7,358.9$ & 9.9 & 727.3 & 24.7 & $\mathbf{1 , 8 1 9 . 5}$ & 43.4 & $3,193.0$ \\
\hline & & \multicolumn{6}{|c|}{ Headcount $-5 \%$ hit on per capita welfare } \\
\hline \multirow{2}{*}{\multicolumn{2}{|c|}{ Aggregate }} & \multicolumn{2}{|c|}{$\$ 1.90$ a day } & \multicolumn{2}{|c|}{$\$ 3.20$ a day } & \multicolumn{2}{|c|}{$\$ 5.50$ a day } \\
\hline & & $\%$ & Mill. & $\%$ & Mill. & $\%$ & Mill. \\
\hline East Asia and Pacific & & 1.6 & 33.1 & 8.8 & 180.2 & 27.9 & 568.3 \\
\hline Europe and Central Asia & & 1.4 & 6.7 & 5.0 & 24.8 & 13.2 & 65.0 \\
\hline Latin America and the Caribbean & & 4.8 & 29.8 & 11.3 & 70.4 & 26.0 & 161.6 \\
\hline Middle East and North Africa & & 8.0 & 30.3 & 21.8 & 81.9 & 47.3 & 177.9 \\
\hline Other high Income & & 0.7 & 7.0 & 0.9 & 9.4 & 1.4 & 14.3 \\
\hline South Asia & & 13.4 & 233.2 & 49.2 & 853.1 & 81.4 & $1,411.7$ \\
\hline Sub-Saharan Africa & & 44.2 & 467.4 & 69.2 & 732.7 & 86.8 & 918.5 \\
\hline \multicolumn{2}{|l|}{ World Total } & 11.0 & 807.5 & 26.5 & $1,952.5$ & 45.1 & $3,317.5$ \\
\hline \multirow{3}{*}{\multicolumn{2}{|c|}{ Aggregate }} & \multicolumn{6}{|c|}{ Headcount - $10 \%$ hit on per capita welfare } \\
\hline & & \multicolumn{2}{|c|}{$\$ 1.90$ a day } & \multicolumn{2}{|c|}{$\$ 3.20$ a day } & \multicolumn{2}{|c|}{$\$ 5.50$ a day } \\
\hline & & $\%$ & Mill. & $\%$ & Mill. & $\%$ & Mill. \\
\hline East Asia and Pacific & & 2.0 & 40.5 & 10.2 & 208.4 & 30.2 & 617.0 \\
\hline Europe and Central Asia & & 1.6 & 7.9 & 5.6 & 27.7 & 14.4 & 71.1 \\
\hline Latin America and the Caribbean & & 5.3 & 32.7 & 12.4 & 77.0 & 28.0 & 174.0 \\
\hline Middle East and North Africa & & 8.9 & 33.7 & 24.1 & 90.6 & 50.1 & 188.5 \\
\hline Other high Income & & 0.7 & 7.4 & 0.9 & 9.5 & 1.4 & 14.8 \\
\hline South Asia & & 16.1 & 280.0 & 53.2 & 923.3 & 83.5 & $1,447.7$ \\
\hline Sub-Saharan Africa & & 46.9 & 496.8 & 71.6 & 757.6 & 87.9 & 930.7 \\
\hline \multicolumn{2}{|l|}{ World Total } & 12.2 & 898.8 & 28.5 & $2,094.1$ & 46.8 & $3,443.7$ \\
\hline \multirow{3}{*}{\multicolumn{2}{|c|}{ Aggregate }} & \multicolumn{6}{|c|}{ Headcount - $20 \%$ hit on per capita welfare } \\
\hline & & \multicolumn{2}{|c|}{$\$ 1.90$ a day } & \multicolumn{2}{|c|}{$\$ 3.20$ a day } & $\$ 5.50$ & day \\
\hline & & $\%$ & Mill. & $\%$ & Mill. & $\%$ & Mill. \\
\hline East Asia and Pacific & & 3.0 & 61.4 & 13.5 & 276.3 & 36.1 & 735.4 \\
\hline Europe and Central Asia & & 2.2 & 10.8 & 7.0 & 34.5 & 17.3 & 85.6 \\
\hline Latin America and the Caribbean & & 6.4 & 39.7 & 14.9 & 92.5 & 32.6 & 202.8 \\
\hline Middle East and North Africa & & 11.3 & 42.4 & 29.2 & 109.8 & 55.9 & 210.2 \\
\hline Other high Income & & 0.7 & 7.5 & 1.0 & 10.0 & 1.7 & 17.3 \\
\hline South Asia & & 23.2 & 401.9 & 61.5 & $1,066.8$ & 87.3 & $1,514.7$ \\
\hline Sub-Saharan Africa & & 52.8 & 558.7 & 76.1 & 805.6 & 90.1 & 954.2 \\
\hline World Total & & 15.3 & $1,122.3$ & 32.6 & $2,395.5$ & 50.6 & $3,720.3$ \\
\hline
\end{tabular}

Source: authors' estimates based on PovcalNet. 
Table A2: Additional poverty as a result of per capita income/consumption contractions (millions)

\begin{tabular}{|c|c|c|c|c|c|c|c|}
\hline \multirow{2}{*}{ Aggregate } & \multicolumn{4}{|c|}{ Number of poor at $\$ 1.90$ a day } & \multicolumn{3}{|c|}{ Additional poor } \\
\hline & Status quo & $5 \%$ hit & $10 \%$ hit & $20 \%$ hit & $5 \%$ hit & $10 \%$ hit & $20 \%$ hit \\
\hline East Asia and Pacific & 27.3 & 33.1 & 40.5 & 61.4 & 5.9 & 13.2 & 34.1 \\
\hline Europe and Central Asia & 5.9 & 6.7 & 7.9 & 10.8 & 0.8 & 2.0 & 4.9 \\
\hline Latin America and the Caribbea & 27.3 & 29.8 & 32.7 & 39.7 & 2.4 & 5.4 & 12.4 \\
\hline Middle East and North Africa & 27.0 & 30.3 & 33.7 & 42.4 & 3.2 & 6.6 & 15.4 \\
\hline Other high Income & 7.0 & 7.0 & 7.4 & 7.5 & 0.0 & 0.4 & 0.5 \\
\hline South Asia & 192.7 & 233.2 & 280.0 & 401.9 & 40.5 & 87.2 & 209.2 \\
\hline Sub-Saharan Africa & 440.2 & 467.4 & 496.8 & 558.7 & 27.2 & 56.6 & 118.5 \\
\hline World Total & 727.3 & 807.5 & 898.8 & $1,122.3$ & 80.1 & 171.5 & 395.0 \\
\hline \multirow{2}{*}{ Aggregate } & \multicolumn{4}{|c|}{ Number of poor at $\$ 3.20$ a day } & \multicolumn{3}{|c|}{ Additional poor } \\
\hline & Status quo & $5 \%$ hit & $10 \%$ hit & $20 \%$ hit & $5 \%$ hit & $10 \%$ hit & $20 \%$ hit \\
\hline East Asia and Pacific & 155.5 & 180.2 & 208.4 & 276.3 & 24.7 & 53.0 & 120.8 \\
\hline Europe and Central Asia & 22.1 & 24.8 & 27.7 & 34.5 & 2.6 & 5.5 & 12.3 \\
\hline Latin America and the Caribbea & 64.7 & 70.4 & 77.0 & 92.5 & 5.7 & 12.4 & 27.9 \\
\hline Middle East and North Africa & 74.5 & 81.9 & 90.6 & 109.8 & 7.4 & 16.1 & 35.3 \\
\hline Other high Income & 8.4 & 9.4 & 9.5 & 10.0 & 1.0 & 1.1 & 1.6 \\
\hline South Asia & 786.7 & 853.1 & 923.3 & $1,066.8$ & 66.3 & 136.5 & 280.0 \\
\hline Sub-Saharan Africa & 707.6 & 732.7 & 757.6 & 805.6 & 25.1 & 50.0 & 98.0 \\
\hline World Total & $1,819.5$ & $1,952.5$ & $2,094.1$ & $2,395.5$ & 133.0 & 274.5 & 576.0 \\
\hline \multirow{2}{*}{ Aggregate } & \multicolumn{4}{|c|}{ Number of poor at $\$ 5.50$ a day } & \multicolumn{3}{|c|}{ Additional poor } \\
\hline & Status quo & $5 \%$ hit & $10 \%$ hit & $20 \%$ hit & $5 \%$ hit & $10 \%$ hit & $20 \%$ hit \\
\hline East Asia and Pacific & 521.3 & 568.3 & 617.0 & 735.4 & 47.0 & 95.7 & 214.1 \\
\hline Europe and Central Asia & 59.7 & 65.0 & 71.1 & 85.6 & 5.3 & 11.3 & 25.9 \\
\hline Latin America and the Caribbea & 150.5 & 161.6 & 174.0 & 202.8 & 11.2 & 23.5 & 52.3 \\
\hline Middle East and North Africa & 168.4 & 177.9 & 188.5 & 210.2 & 9.6 & 20.1 & 41.8 \\
\hline Other high Income & 13.1 & 14.3 & 14.8 & 17.3 & 1.2 & 1.7 & 4.2 \\
\hline South Asia & $1,374.1$ & $1,411.7$ & $1,447.7$ & $1,514.7$ & 37.6 & 73.6 & 140.5 \\
\hline Sub-Saharan Africa & 905.9 & 918.5 & 930.7 & 954.2 & 12.6 & 24.8 & 48.3 \\
\hline World Total & $3,193.0$ & $3,317.5$ & $3,443.7$ & $3,720.3$ & 124.4 & 250.7 & 527.2 \\
\hline
\end{tabular}

Source: authors' estimates based on PovcalNet.

Table A3. Additional poverty at $\$ 1.90$ a day in top 25 contributors as a result of per capita income/consumption contractions (percentage points and millions of poor; ranked by additional poor under a $5 \%$ contraction scenario)

\begin{tabular}{|c|c|c|c|c|c|c|c|c|}
\hline \multirow{2}{*}{ Country } & \multicolumn{2}{|c|}{ Headcount in status quo } & \multicolumn{3}{|c|}{ In crease in head count ratio (pp) } & \multicolumn{3}{|c|}{ Absolute in crease (m illion s) } \\
\hline & Ratio & Million s & $5 \%$ hit & $10 \%$ hit & $20 \%$ hit & 5\% hit & $10 \%$ hit & $20 \%$ hit \\
\hline India & 13.3 & 174.9 & 2.7 & 5.7 & 13.6 & 35.4 & 75.2 & 178.5 \\
\hline Nigeria & 50.8 & 99.6 & 2.5 & 5.6 & 11.6 & 5.0 & 11.0 & 22.6 \\
\hline Ethiopia & 22.3 & 24.4 & 3.2 & 6.7 & 14.2 & 3.5 & 7.3 & 15.5 \\
\hline Bangladesh & 7.8 & 12.6 & 1.9 & 4.4 & 11.0 & 3.1 & 7.1 & 17.7 \\
\hline Indonesia & 4.6 & 12.4 & 1.1 & 2.4 & 6.1 & 2.9 & 6.4 & 16.2 \\
\hline Congo, Democratic Republic of & 70.7 & 59.5 & 2.4 & 4.6 & 9.0 & 2.1 & 3.8 & 7.6 \\
\hline Tanzania & 49.0 & 27.6 & 3.4 & 6.8 & 13.8 & 1.9 & 3.9 & 7.8 \\
\hline Pakistan & 1.6 & 3.4 & 0.8 & 1.9 & 4.9 & 1.6 & 4.0 & 10.4 \\
\hline Kenya & 32.6 & 16.8 & 2.8 & 6.1 & 12.8 & 1.5 & 3.2 & 6.6 \\
\hline Uganda & 40.2 & 17.2 & 3.1 & 6.3 & 13.2 & 1.3 & 2.7 & 5.7 \\
\hline Philippines & 4.6 & 4.9 & 1.1 & 2.3 & 6.0 & 1.1 & 2.5 & 6.4 \\
\hline Yemen, Republic of & 51.9 & 14.8 & 3.9 & 7.6 & 14.3 & 1.1 & 2.2 & 4.1 \\
\hline Egypt, Arab Republic of & 3.2 & 3.2 & 1.0 & 2.1 & 6.0 & 1.0 & 2.1 & 5.9 \\
\hline Sudan & 12.1 & 5.1 & 2.1 & 4.2 & 10.9 & 0.9 & 1.8 & 4.6 \\
\hline China & 0.3 & 3.7 & 0.1 & 0.2 & 0.5 & 0.9 & 2.1 & 6.3 \\
\hline Burkina Faso & 34.8 & 6.9 & 4.3 & 8.6 & 17.7 & 0.8 & 1.7 & 3.5 \\
\hline South Africa & 19.5 & 11.3 & 1.5 & 3.0 & 7.2 & 0.8 & 1.7 & 4.1 \\
\hline Niger & 41.3 & 9.3 & 3.6 & 8.1 & 15.0 & 0.8 & 1.8 & 3.4 \\
\hline Mali & 42.7 & 8.1 & 3.9 & 7.6 & 15.1 & 0.7 & 1.5 & 2.9 \\
\hline Brazil & 4.4 & 9.3 & 0.3 & 0.7 & 1.6 & 0.7 & 1.5 & 3.3 \\
\hline Syrian Arab Republic & 43.4 & 7.3 & 3.9 & 7.8 & 15.8 & 0.7 & 1.3 & 2.7 \\
\hline Mozambique & 61.1 & 18.0 & 2.2 & 4.4 & 9.3 & 0.6 & 1.3 & 2.8 \\
\hline Angola & 47.1 & 14.5 & 2.0 & 4.8 & 10.0 & 0.6 & 1.5 & 3.1 \\
\hline Cote d'Ivoire & 21.5 & 5.4 & 2.3 & 4.7 & 10.7 & 0.6 & 1.2 & 2.7 \\
\hline Malawi & 69.3 & 12.6 & 3.2 & 5.6 & 10.5 & 0.6 & 1.0 & 1.9 \\
\hline Rest of countries & & & & & & 9.8 & 21.4 & 48.4 \\
\hline
\end{tabular}

Note: rest of countries also includes high-income countries.

Source: authors' estimates based on PovcalNet. 
Table A4: Additional poverty at $\$ 3.20$ a day in top 25 contributors as a result of per capita income/consumption contractions (percentage points and millions of poor; ranked by additional poor under a $5 \%$ contraction scenario)

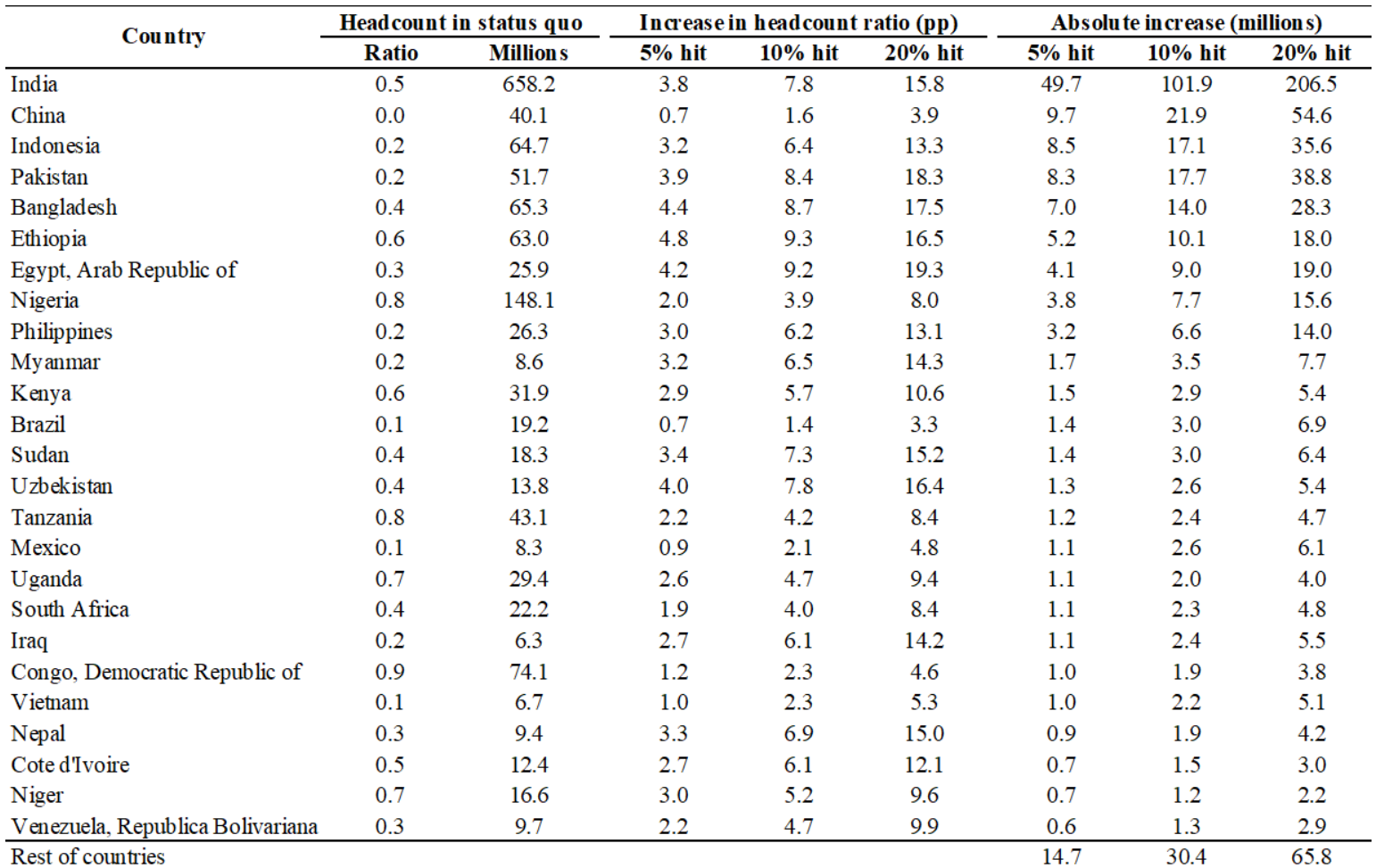

Note: rest of countries also includes high-income countries.

Source: authors' estimates based on PovcalNet.

Table A5: Additional poverty at $\$ 5.50$ a day in top 25 contributors as a result of per capita income/consumption contractions (percentage points and millions of poor; ranked by additional poor under a $5 \%$ contraction scenario)

\begin{tabular}{|c|c|c|c|c|c|c|c|c|}
\hline \multirow{2}{*}{ Country } & \multicolumn{2}{|c|}{ Headcount in status quo } & \multicolumn{3}{|c|}{ Increase in headcount ratio (pp) } & \multicolumn{3}{|c|}{ Absolute increase (millions) } \\
\hline & Ratio & Millions & $5 \%$ hit & $10 \%$ hit & $20 \%$ hit & $5 \%$ hit & $10 \%$ hit & $20 \%$ hit \\
\hline Bangladesh & 0.8 & 125.8 & 2.3 & 4.6 & 8.9 & 3.8 & 7.4 & 14.3 \\
\hline Colombia & 0.3 & 13.8 & 2.1 & 4.2 & 9.6 & 1.0 & 2.1 & 4.8 \\
\hline Cameroon & 0.7 & 16.5 & 2.6 & 5.1 & 9.9 & 0.7 & 1.3 & 2.5 \\
\hline Argentina & 0.1 & 3.9 & 0.9 & 2.0 & 5.0 & 0.4 & 0.8 & 2.1 \\
\hline Angola & 0.9 & 26.8 & 1.2 & 2.3 & 4.6 & 0.4 & 0.7 & 1.4 \\
\hline Bolivia & 0.2 & 2.6 & 1.8 & 4.2 & 8.8 & 0.2 & 0.5 & 1.0 \\
\hline Burkina Faso & 0.9 & 17.9 & 0.9 & 1.8 & 3.5 & 0.2 & 0.4 & 0.7 \\
\hline Armenia & 0.5 & 1.5 & 3.6 & 7.8 & 17.2 & 0.1 & 0.2 & 0.5 \\
\hline Burundi & 1.0 & 10.9 & 0.4 & 0.7 & 1.0 & 0.1 & 0.1 & 0.1 \\
\hline Bulgaria & 0.1 & 0.5 & 0.7 & 1.3 & 3.3 & 0.05 & 0.1 & 0.2 \\
\hline Botswana & 0.6 & 1.3 & 1.9 & 4.0 & 8.3 & 0.04 & 0.1 & 0.2 \\
\hline Bhutan & 0.3 & 0.2 & 3.1 & 6.1 & 12.7 & 0.02 & 0.04 & 0.1 \\
\hline Central A frican Republic & 0.9 & 4.4 & 0.3 & 0.8 & 1.4 & 0.02 & 0.04 & 0.1 \\
\hline Bosnia and Herzegovina & 0.0 & 0.1 & 0.4 & 0.8 & 2.1 & 0.01 & 0.03 & 0.1 \\
\hline Belarus & 0.0 & 0.0 & 0.1 & 0.3 & 0.7 & 0.01 & 0.03 & 0.1 \\
\hline Belize & 0.5 & 0.2 & 2.4 & 4.1 & 8.9 & 0.01 & 0.01 & 0.03 \\
\hline Azerbaijan & 0.0 & 0.0 & 0.0 & 0.0 & 0.1 & 0.00 & 0.00 & 0.01 \\
\hline Rest of countries & & & & & & 82.1 & 165.5 & 334.9 \\
\hline
\end{tabular}

Note: rest of countries also includes high-income countries.

Source: authors' estimates based on PovcalNet. 